\title{
Interpretation of osteoporotic vertebral deformity on frontal view radiographs of the chest and abdomen: a pictorial review
}

\author{
Yì Xiáng J. Wáng ${ }^{1}$, Er-Zhu Du ${ }^{2}$, Jingshan Gong ${ }^{3}$, Xiaoguang Cheng ${ }^{4}$ \\ ${ }^{1}$ Department of Imaging and Interventional Radiology, Faculty of Medicine, The Chinese University of Hong Kong, Shatin, New Territories, Hong \\ Kong SAR, China; ${ }^{2}$ Department of Radiology, Dongguan Traditional Chinese Medicine Hospital, Dongguan, China; ${ }^{3}$ Department of Radiology, \\ Shenzhen People's Hospital (The Second Clinical Medical College, Jinan University; The First Affiliated Hospital, Southern University of Science \\ and Technology), Shenzhen, China; ${ }^{4}$ Department of Radiology, Beijing Jishuitan Hospital, Beijing, China
}

Correspondence to: Dr. Yì Xiáng J. Wáng. Department of Imaging and Interventional Radiology, Faculty of Medicine, The Chinese University of Hong Kong, Shatin, New Territories, Hong Kong SAR, China. Email: yixiang_wang@cuhk.edu.hk.

\begin{abstract}
Osteoporotic vertebral fracture (OVF) has high prevalence in the elderly population. It affects at least one-fourth of all postmenopausal women and is commonly seen among women approximately one decade after menopause. A vertebral fracture, after minor trauma, is a hallmark of osteoporosis. Many fractures and associated complications, including secondary fractures and mortality, can be prevented by routine osteoporosis screening in older people and timely treatment initiation in at-risk individuals. Depending on the technical condition of the radiographs, a substantial portion of moderate to severe grades OVFs in mid-thoracic and lower thoracic spine as well as lumbar spine can be detected on a frontal view digital radiograph of the chest or abdomen. Radiologists should pay attention to the potential existence of an OVF while reading chest and abdominal radiographs of elderly female subjects. In this pictorial review, we describe our experience in evaluating the normal shaped and deformed vertebrae on chest and abdominal radiographs.
\end{abstract}

Keywords: Osteoporosis; vertebral fracture; radiograph; chest; abdomen; vertebral deformity.

Submitted Aug 27, 2020. Accepted for publication Sep 21, 2020.

doi: 10.21037/qims-2020-28

View this article at: http://dx.doi.org/10.21037/qims-2020-28

Osteoporosis is a systemic skeletal disease characterised by a reduction in bone mass and qualitative skeletal changes that cause an increase in bone fragility and higher fracture risk. Primary osteoporosis is considered to have two etiologic variants. Type I affects postmenopausal women and is related to rapid loss of bone after menopause, whereas type II affects individuals over 70 years old and involves age-related loss of bone or senile osteoporosis. Secondary osteoporosis is loss of bone caused by an agent or disease process such as corticosteroids, endocrine disorders, or an inflammatory process. Fragility fractures may occur in almost all skeletal segments, but the preferential locations are the vertebral column, the proximal ends of the femur and humerus, and the distal end of the radius (Colles fracture). Trauma due to a fall is by far the most frequent cause of fractures affecting long bones, while it is more difficult to determine the cause and the exact time of fragility fractures of the vertebral body, which often go undiagnosed. Osteoporotic vertebral fracture (OVF) has high prevalence in the elderly population. It affects at least one-fourth of all postmenopausal women and is commonly seen among women approximately one decade after menopause. A vertebral fracture, after minor trauma, is a hallmark of osteoporosis. The detection of OVF in women suggest that the patient's bone strength is compromised, and the risk of future fracture is substantially increased, both for further OVF and non-vertebral fragility fracture including the hip (1-5). Hip fractures have highly detrimental and 
very costly individual and social repercussions; in women over 55 years and older, they are responsible for more hospitalisations than heart attacks, strokes, and breast cancer combined (6). OVFs can be associated with decreases in trunk extension torque, spinal motion, functional reach, mobility skills and walking distance, and may also influence mortality because their association with chronic back pain, immobility and postural change (7). Multiple and more severe grades of OVFs are associated with an even greater fracture risk $(1,2,8)$.

Advances in understanding the biology of osteoporosis have resulted in several medications that have been demonstrated to reduce fracture risk, both vertebral and nonvertebral, including hip, fractures (9-13). Nonpharmacologic approaches to manage osteoporosis, the combination of weight-bearing and resistance training, and adequate calcium and vitamin $\mathrm{D}$ intake and physical activity, can positively affect bone mass. Coupled with preventing falls and limiting modifiable risk factors, such as smoking and alcohol use, these measures can help reduce a person's risk for osteoporotic fractures $(14,15)$. An early detection of an OVF can lead to further investigation and appropriate therapy that decreases the risk of future fractures, critically to target pharmaceutical treatment to the patents aged 65 years or older with a hip or vertebral fracture (16). Many fractures and associated complications, including secondary fractures and mortality, could be prevented by routine osteoporosis screening in older people and timely treatment initiation in at-risk individuals.

Despite its importance, many patients with OVF and at high risk for further fracture remain undetected and untreated. OVF may often be relatively asymptomatic clinically, it is expected that less than $1 / 4$ radiographic OVFs are diagnosed as clinical incident fractures $(17,18)$. Among women at high risk for fracture, defined as those over 65 years of age and having at least 2 other fracture risk factors, only about one third in USA reported treatment with osteoporosis medication (19). Many guidelines suggest women with age $\geq 60$ or $\geq 65$ years should have osteoporosis screening (3,5,20-23). The International Society for Clinical Densitometry recommends DXA (dual-energy $\mathrm{X}$-ray absorptiometry) assessment for all women and men aged $\geq 65$ and $\geq 70$ years, respectively (24). However, this measure is still not commonly taken by individuals. On the other hand, in clinical practice, frontal radiograph (FR) of the chest is often taken for patients suspected of respiratory diseases, pleural diseases, as well as to assess heart and big vessels, while chest lateral radiograph (LR) is taken less often for these purposes. FR of abdomen is taken in patients with abdominal pain, for assessing urinary stone, gastrointestinal gas etc. Based on the analysis of digital spine radiograph which allows convenient adjustment of brightness and contrast of the images, we reported that moderate to severe vertebral deformities (VDs, i.e., with $>25 \%$ vertebral height loss) at mid-thoracic and lower thoracic spine as well as lumbar spine are mostly identifiable on the FR, with a small proportion of ambiguous cases further clarified by additional lateral view imaging (25). Moreover, some mild VD and endplate and/or cortical fracture (ECF) are also visible on FR (25). It can be envisaged that, depending on the technical condition of the radiographs, a substantial portion of moderate to severe grades VDs can also be detected on FRs of the chest and abdomen. VD is the appearance of OVF (though not necessarily every VD is an OVF). Opportunity exists for detecting OVFs on digital chest/abdominal FR for highrisk osteoporotic patients (such as elderly females $>65$ years) when they are X-rayed for other indications. Radiologists should pay attention to the potential existence of an OVF while reading chest and abdominal RFs of elderly subjects. Once an OVF is identified, to prevent secondary fracture, a multidisciplinary case management approach that takes the form of a fracture liaison service (FLS) can be established, which has been shown to be the most effective organizational approach (26). Patient should also receive education to encourage live a healthy lifestyle, to raise selfawareness about the disease and to become involved in selfcare management $(27,28)$.

FRs of chest are mostly commonly taken posterioranteriorly (PA), i.e., the anterior chest wall is closed to the $\mathrm{X}$-ray detector. Since the spine is at the back of the chest, compared with spine RFs which are taken with the spine close to the $\mathrm{X}$-ray detector, the vertebrae are magnified on FR to some extent and the borders are blurrier. Moreover, FRs of chest are mostly used for detecting lung diseases. Since lung, filled with air, absorbs much less X-ray than abdominal organs, chest FRs are commonly taken with much less mAs (milli-Ampere-seconds) than that of the abdominal FR and spine FR. On the other hand, FRs of abdomen are mostly commonly taken on anteriorposteriorly (AP, mostly in a supine position), i.e., the lower back is closed to the $\mathrm{X}$-ray detector. Thus, the vertebral 
borders on abdominal FR are usually sharp. The most frequent site of OVF involvement is the thoracolumbar junction, with the second most frequent region being the mid-thoracic spine $(29,30)$. One of the difficulties of reading spine on FR of chest and abdomen is that the site of highest prevalence of OVF, i.e., the thoracolumbar junction, is usually 'off-centre' to the X-ray beam. In our experience, this is more a problem for chest FR, where the focus of the $\mathrm{X}$-ray beam is toward mid-thoracic region; T12, L1, and L2, when included in the field of view, may not be well displayed. Till further evidences are available, it is probably prudent that we emphasize the specificity of our interpretation of OVF, and minimised 'false alarm' or 'over-call' for patients when the primary indication for the radiographs is not OVF screening (25). X-ray cone-beam may cause geometric distortion of vertebrae located at extremities of the scans, and the accuracy of diagnosis of VCFs can also be reduced at the upper thoracic levels. Upper thoracic spine is also often associated with physiological kyphosis; however, it has been known that OVF at levels above T6 is less common (29,30).

For OVF high risk patients with suspected VDs or definite VDs on FR, additional LR or DXA imaging based VFA (vertebral fracture assessment, or other imaging modalities such as CT/magnetic resonance imaging when indicated) should be recommended. This can not only confirm (or refute) the suspected VFs on FR, lateral imaging also helps to grade the OVF and detect possible additional $\mathrm{VF}(\mathrm{s})$ missed on FR. Multiple OVFs is a strong indication for initiation of anti-osteoporosis treatment. In assessing a vertebra, there are usually three stepwise questions: (I) does a VD exist? (II) is this VD likely a compressive VD? (III) can this compressive VD be called OVF? Currently, the differentiation of what is compressive VD and what is OVF has not been well defined. Some investigators choose to call VDs of Genant semi-quantitative (SQ) grade-2 and above (i.e., those compressive VD with $\geq 25 \%$ height loss) as OVF, while call SQ grade-1 compressive VD as osteoporotic VD. Some authors suggest that OVD is OVF only when diagnosed on the basis of evidence or findings of endplate, cortical, or trabecular damage $(31,32)$. It should also be noted that to exclude VDs of non-osteoporotic causes can be difficult in practice, particularly for mild deformities caused by degeneration and old trauma. A 'golden' radiological standard to separate osteoporotic and non-osteoporotic deformities in every case does not exist till now. The age group with high prevalence of OVF is also the age group with high prevalence of spine metastatic tumors. Differentiating between OVD and metastatic deformity can be sometimes difficult by sole radiograph (33). MRI is the preferred imaging technique for differential diagnosis purpose.

To expand our previous report on spine RF assessment of VD (25), we further evaluated the normal shaped and deformed vertebrae of spine on chest and abdominal radiographs and describe our experience in the current pictorial review (Figures 1-31). To facilitate understanding the VD appearance on FR, a number of spine radiographs are also included in this article. All the VD gradings on LR were based on the extended semi-quantitative (eSQ) criteria, where in addition to a qualitative diagnosis of osteoporotic VD, minimal grade, mild grade, moderate grade $(\mathrm{mod} / \mathrm{m})$, moderately-severe $(\mathrm{mod} / \mathrm{s})$ grade, severe grade, and collapsed grade OVDs have vertebral height loss of $<20 \%, 20-25 \%,>25 \%-1 / 3,>1 / 3-40 \%,>40 \%-2 / 3$, and $>2 / 3$, respectively (35). We do not offer grading on FR.

In conclusion, as the clinical management can be improved by opportunistic detection of OVF, radiologists should be trained and sensitized in VD identification in FR. This pictorial review provides 28 examples with VD demonstrated on FR. The best way for radiologists to acquire the skill of interpreting VD on FR is to read lots of examples. In clinical practice, $\mathrm{PA}+$ lateral chest radiographs are commonly taken, so radiologist have lots of opportunities to practice, by reading FR images and the results confirmed by LR. For abdominal radiograph, LR is usually not simultaneously obtained. Since the demonstration of lumbar vertebrae on abdominal FR is similar to spine radiograph, radiologists can practice reading lumbar VD on spine FR (spine LRs are usually taken simultaneously). Readers are also encouraged to refer to the 19 illustrative cases in our previous article (25). The importance of OVF in East Asian men for predicting further osteoporotic fracture risk remains unknown $(36,37)$. We reported that existing severe OVFs in elderly Chinese males were only weakly associated with higher further vertebral fracture risk at year-4 follow-up (37). However, compressive VD commonly occur in men with bone mineral density defined osteoporosis $(36,38)$. After old traumatic deformity, degenerative deformity and other non-osteoporotic deformities are excluded, radiographic compressive VD is a strong indicator that the patient has osteoporosis. 

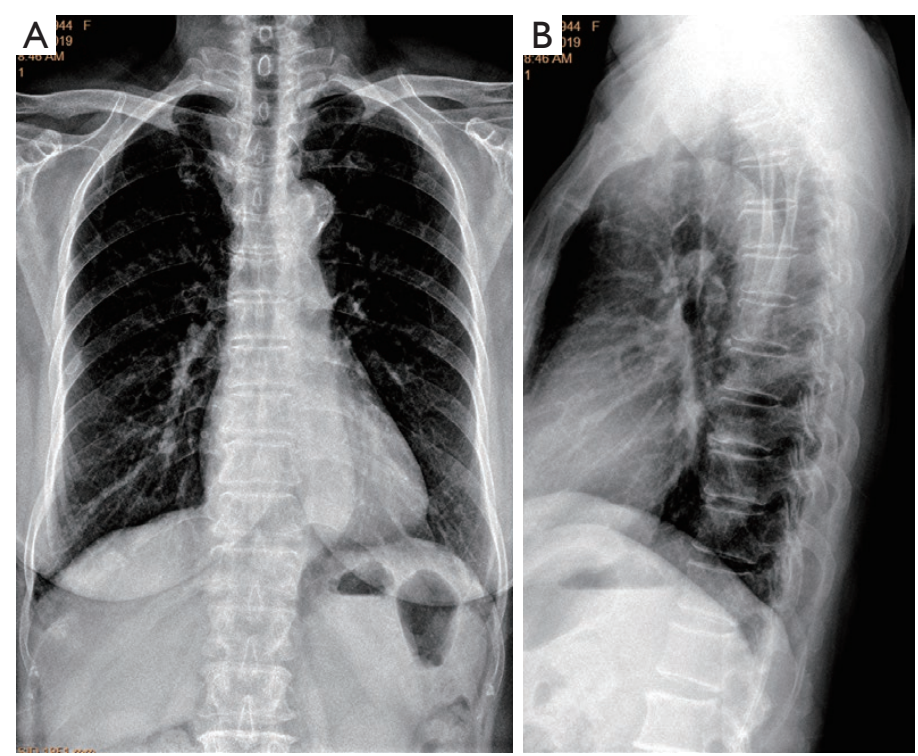

Figure 1 Chest radiographs of a female aged 76 years (A: FR, B: LR). Mid- and lower thoracic vertebrae and L1/L2 vertebrae are displayed on FR with no deformity. Note, compared with AP (anterior to posterior) spine radiograph (see Figures 2-5 below), vertebral body's borders can be slightly blurry due to PA (posterior to anterior) filming when the anterior chest wall is close to the X-ray detector. FR, frontal radiograph; LR, lateral radiograph.
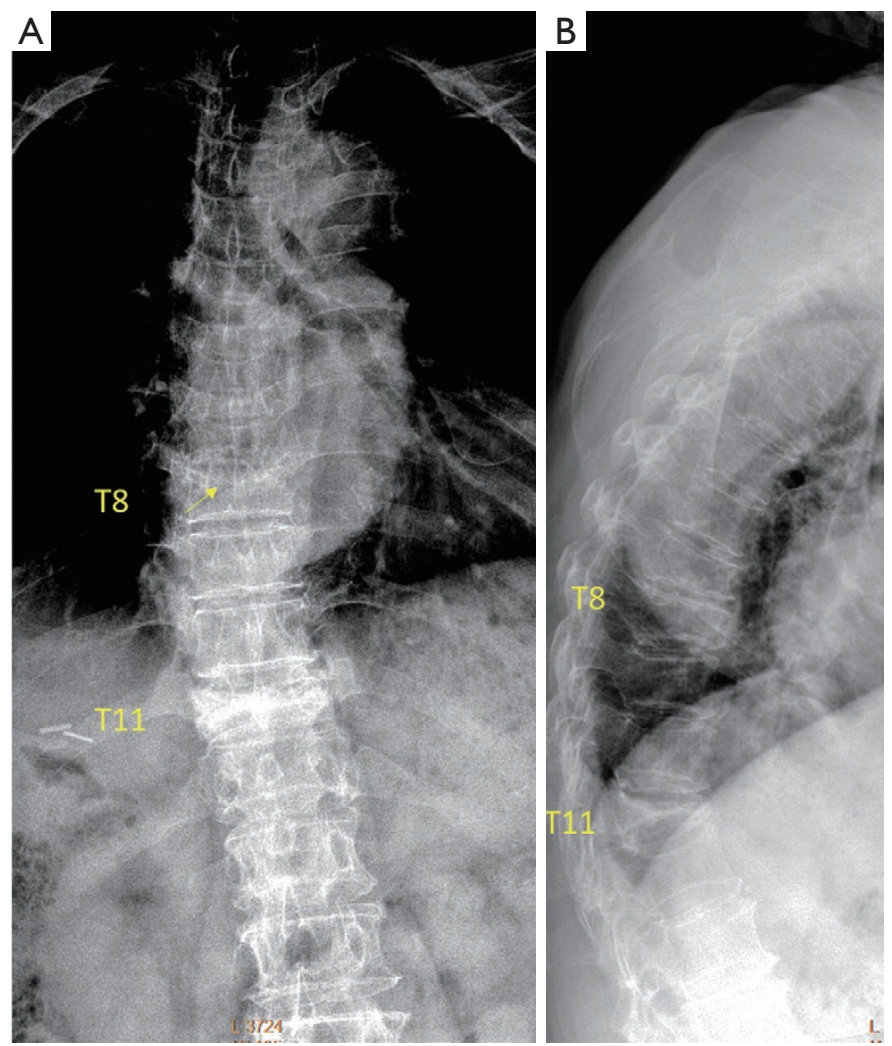

Figure 2 Spine radiograph (A: FR, B: LR). T11 vertebral body is collapsed. T9 and T10 are of normal shape, while T8 (arrow) had a height loss (eSQ $\mathrm{mod} / \mathrm{m} \mathrm{VD)}$. T7 eSQ mod/m VD is not well recognised on FR. FR, frontal radiograph; LR, lateral radiograph; VD, vertebral deformity. 

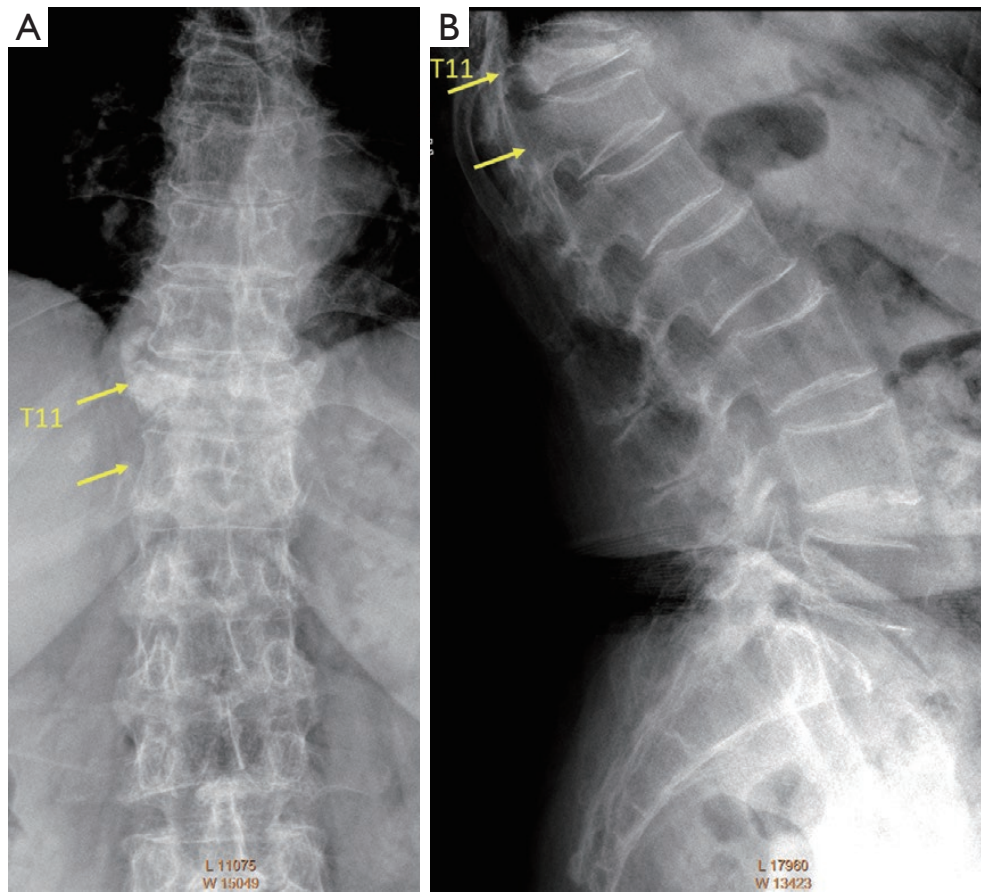

Figure 3 Spine radiograph. T11 vertebral body is collapsed. T12 has eSQ mod/m VD with endplate depression. T11 (arrow) and T12 (arrow) OVF induced local kyphosis. Due to the altered projection of X-ray relative to the L1 and L2 (B), L1 and L2 are poorly displayed on FR (A). OVF, osteoporotic vertebral fracture; FR, frontal radiograph; VD, vertebral deformity.

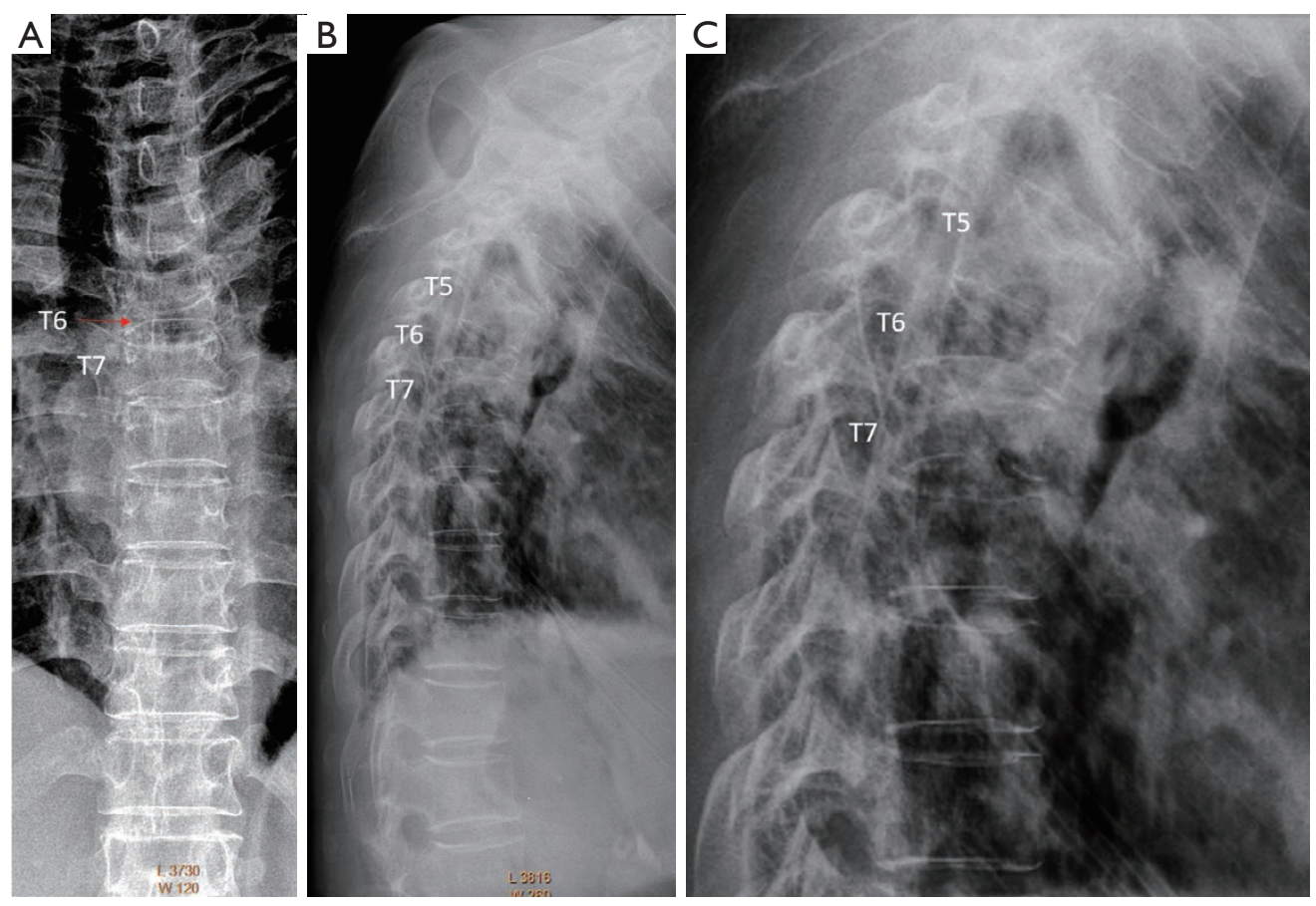

Figure 4 Spine radiograph (A: FR, B/C: LR). T6 vertebral body (arrow) is collapsed which is demonstrated on FR. T7 has VD which is confirmed on LR (eSQ grade mod/m). T5 mild deformity cannot be assessed on FR. FR, frontal radiograph; LR, lateral radiograph; VD, vertebral deformity. 

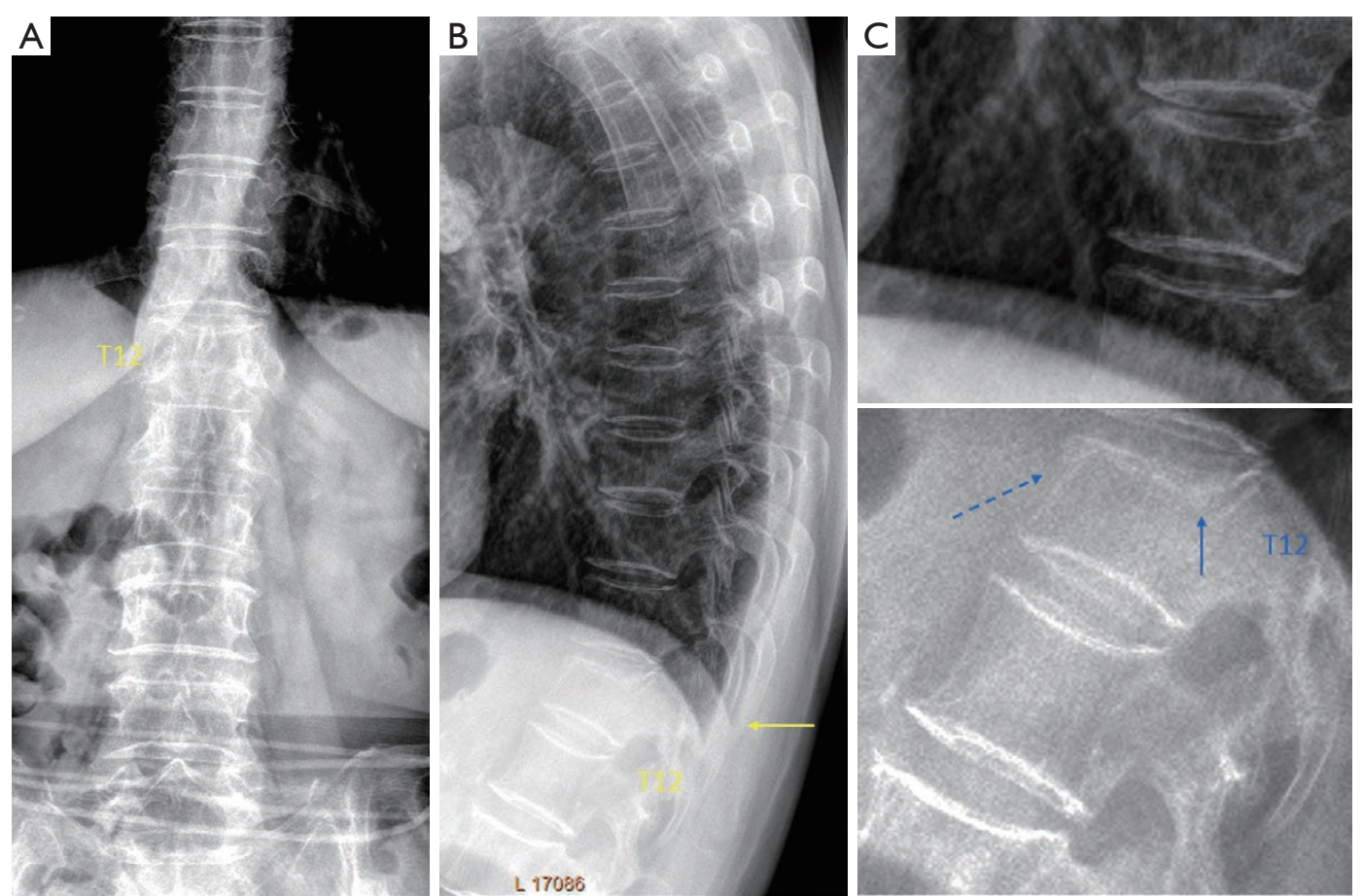

Figure 5 Spine radiographs show T12 VD. FR (A) show T12 has a height loss, and the vertebral upper border is depressed. These changed can be appreciated by comparing with the regular shape of T11. LR (B) show kyphosis around T11/T12 level (arrow), which might be due to T12 VD. (C) is a zoomed-in image of lateral spine at T12 level. T12 has positive ECF sign with upper endplate collapse (blue arrow) and anterior cortex fracture (dotted arrow). Reproduce with permission from reference (25) supplementary materials. FR, frontal radiograph; LR, lateral radiograph; VD, vertebral deformity.
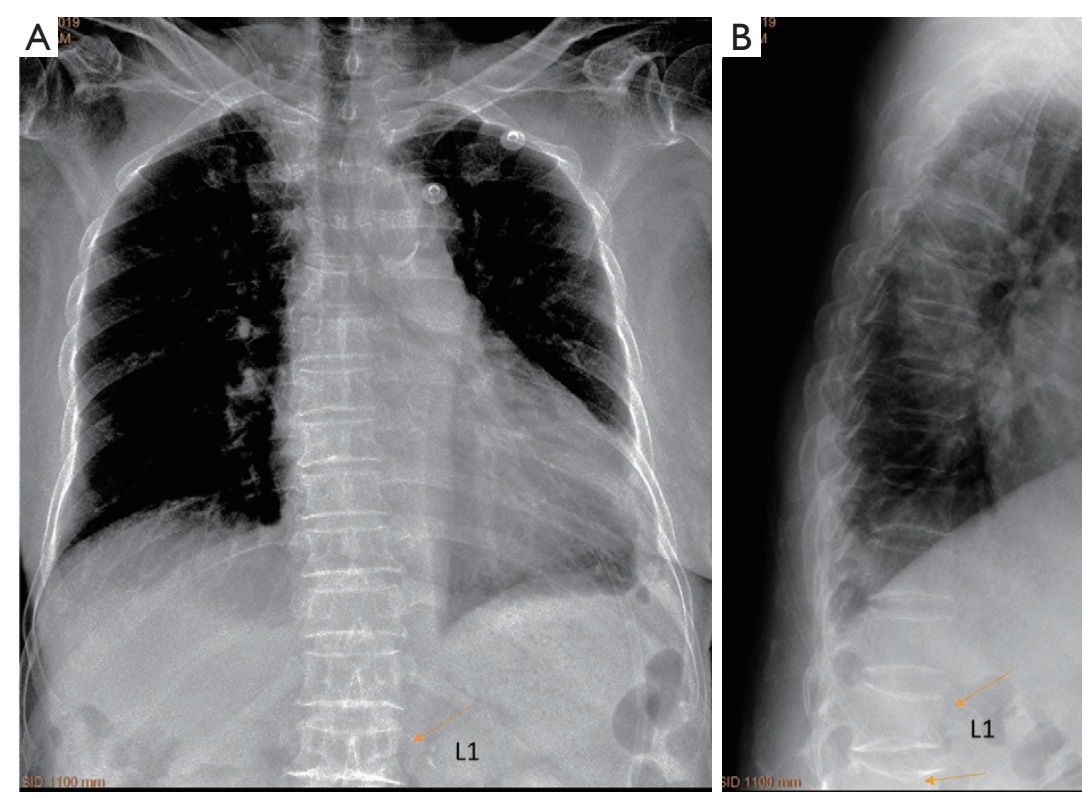

Figure 6 Chest radiographs a female aged 84 years (A: FR, B: LR). FR shows L1 VD (arrow, note both upper and lower endplates depression), which is confirmed by LR showing L1 eSQ mod/m VD (arrow). L2 upper endplate depression is shown on LR (arrow). FR, frontal radiograph; LR, lateral radiograph; VD, vertebral deformity. 

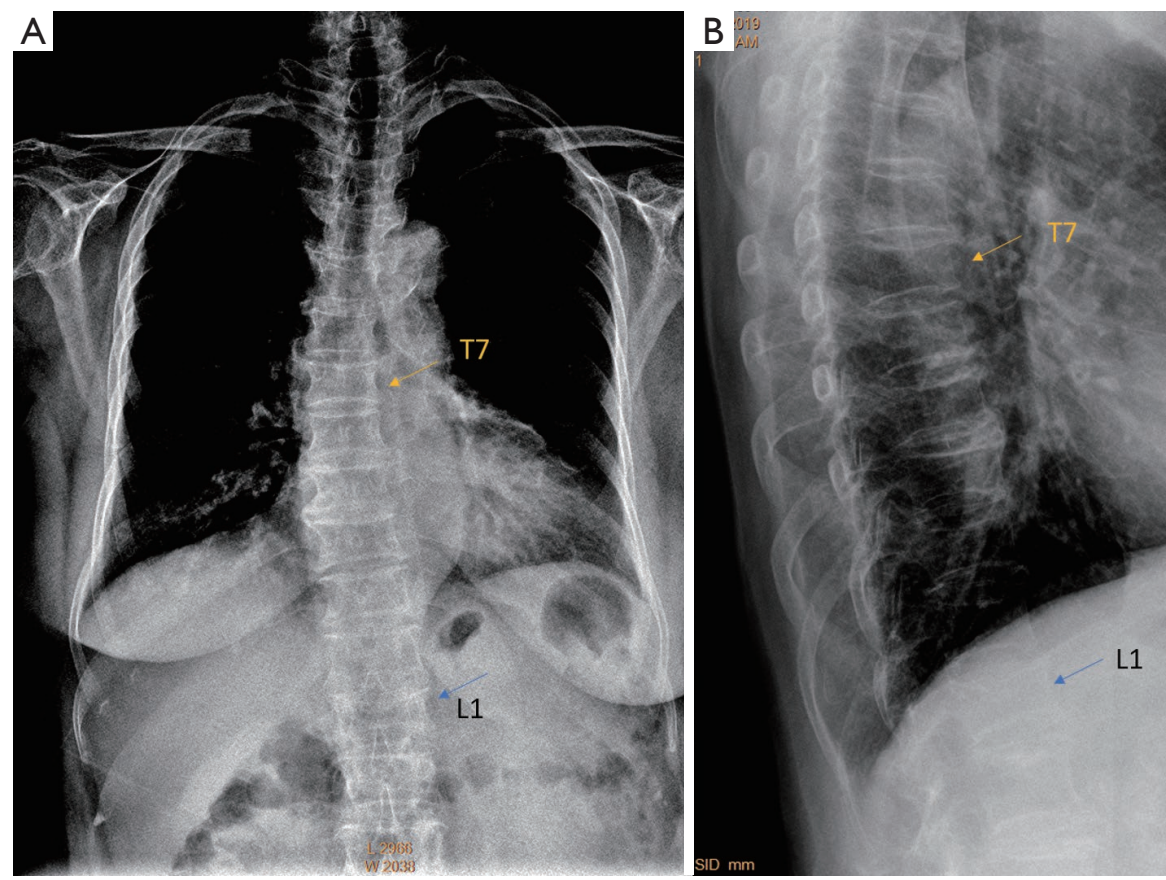

Figure 7 Chest radiographs of a female aged 84 years (A: FR, B: LR). FR shows L1 VD (blue arrow), which is apparent when comparing the normal appearing T12 and L2. L1 VD is confirmed on LR. T7 (orange arrow) has a minimal grade VD which cannot be seen on FR. FR, frontal radiograph; LR, lateral radiograph; VD, vertebral deformity.
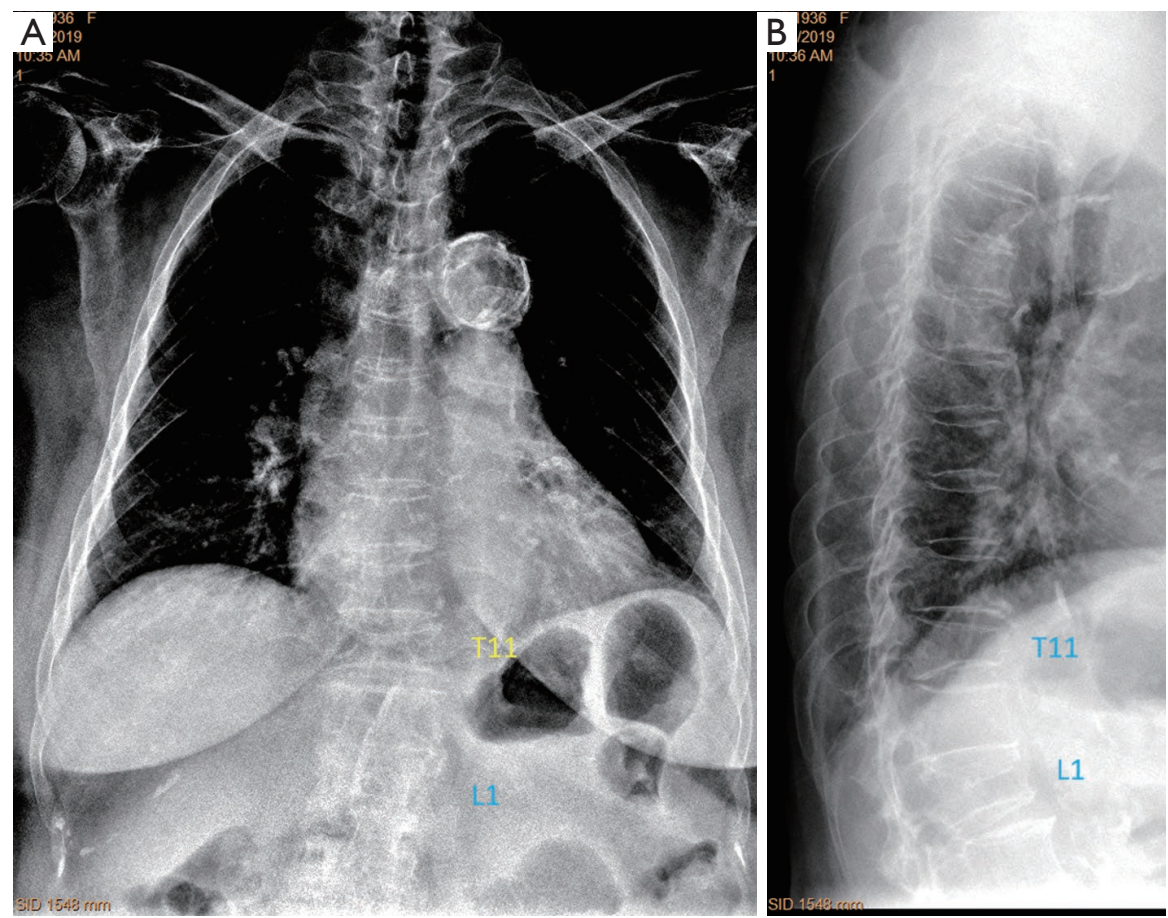

Figure 8 Chest radiographs of a female aged 84 years (A: FR, B: LR). FR shows T11 VD, which is apparent when comparing the shape of T10. FR confirmed T11 to be eSQ mod/s grade. FR also suspect L1 VD (with increased density), FR confirmed L1 eSQ severe grade. FR, frontal radiograph; LR, lateral radiograph; VD, vertebral deformity. 

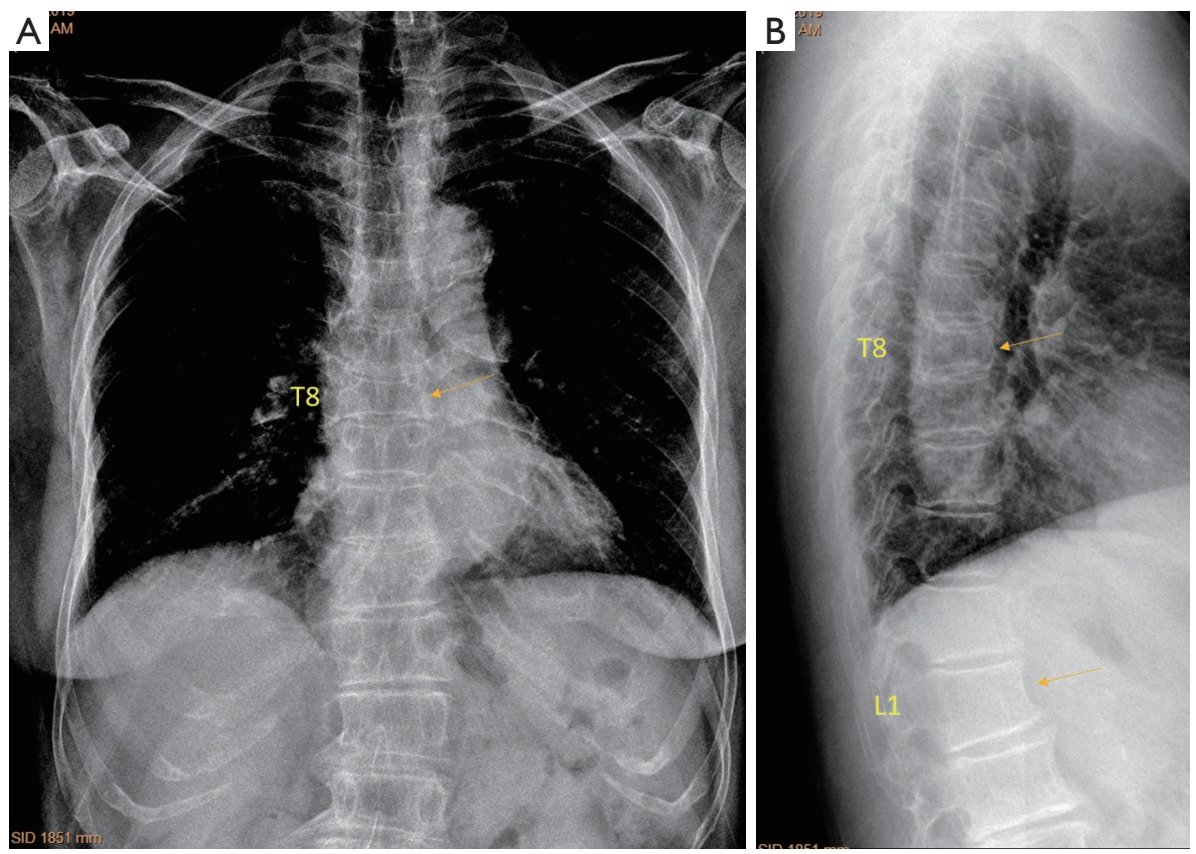

Figure 9 Chest radiographs of a female aged 77 years (A: FR, B: LR). FR shows T8 VD (arrow), which is apparent by comparing the shape of T7 and T9. FR confirms T8 to be eSQ mild VD. LR also suggests L1 eSQ minimal grade VD (arrow) which cannot be seen on FR. FR, frontal radiograph; LR, lateral radiograph; VD, vertebral deformity.
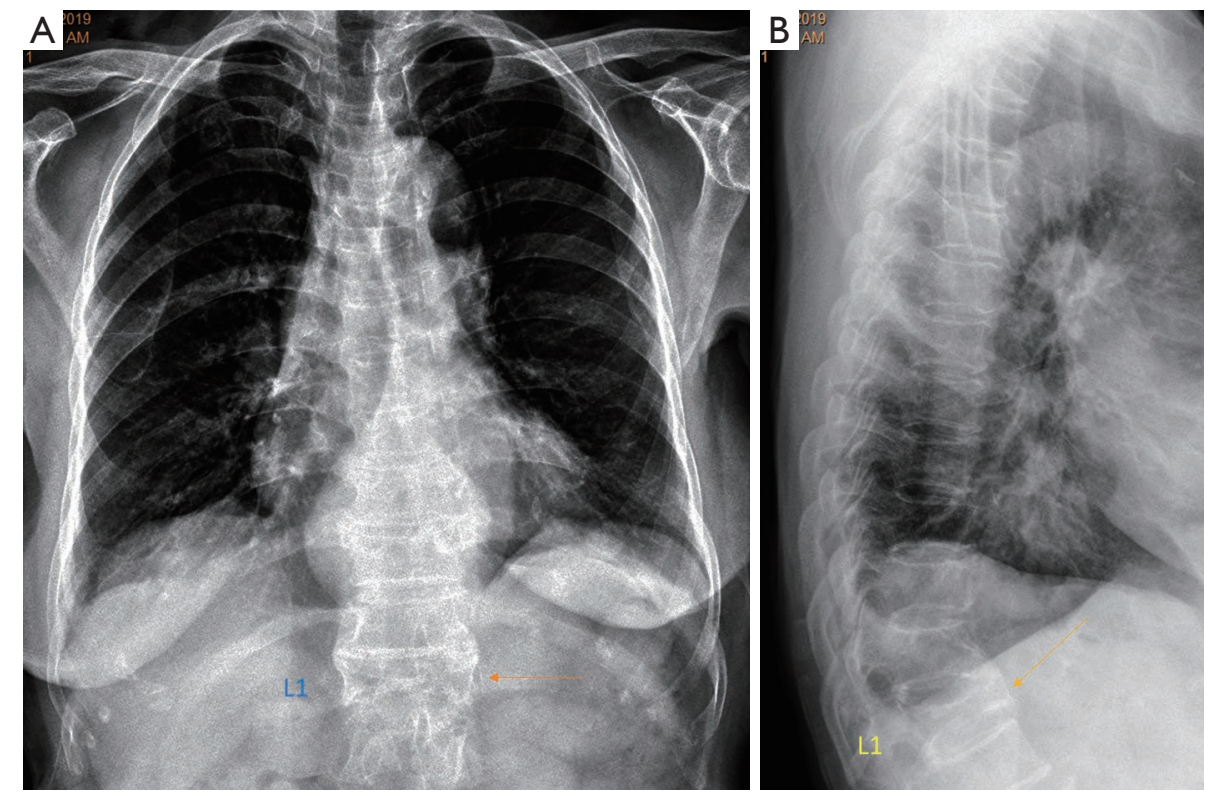

Figure 10 Chest radiographs of a female aged 83 years (A: FR, B: LR). FR shows L1 collapsed deformity (arrow) which is confirmed on LR. FR, frontal radiograph; LR, lateral radiograph. 

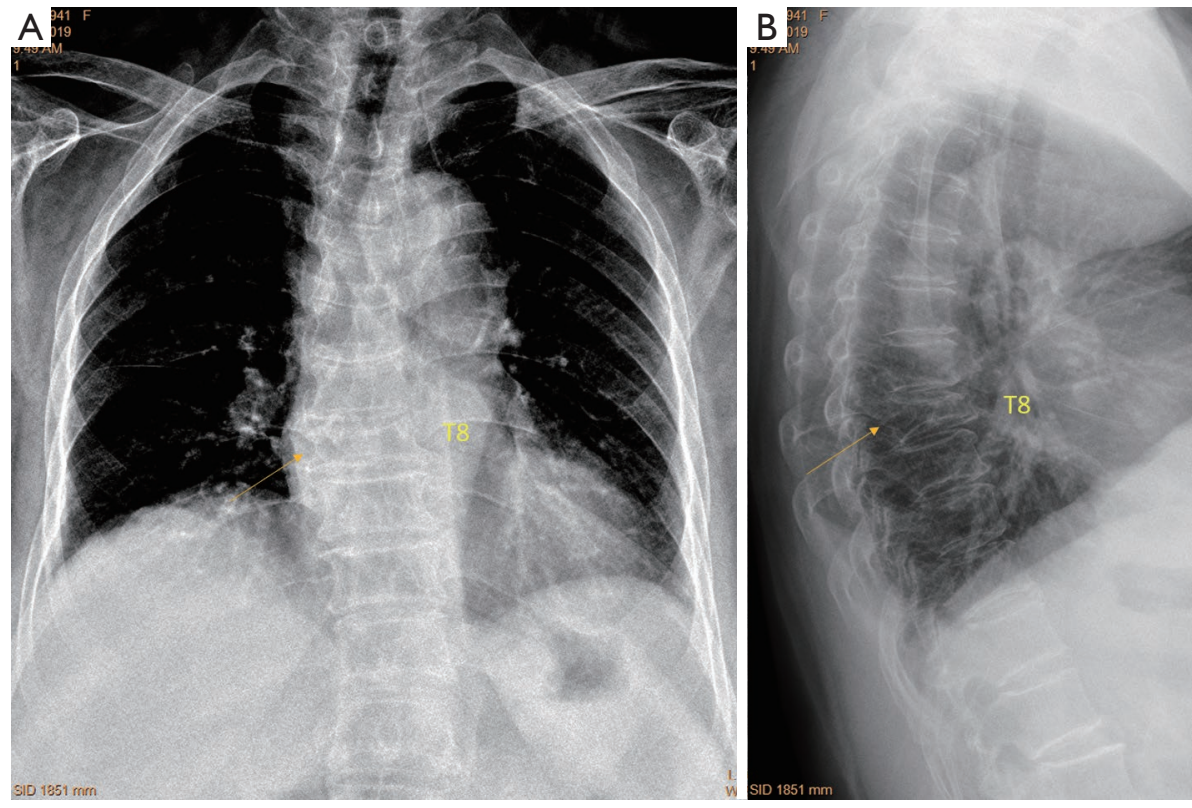

Figure 11 Chest radiographs of a female aged 79 years (A: FR, B: LR). FR show T8 deformity (arrow) which is also shown on LR (eSQ severe grade). FR, frontal radiograph; LR, lateral radiograph.
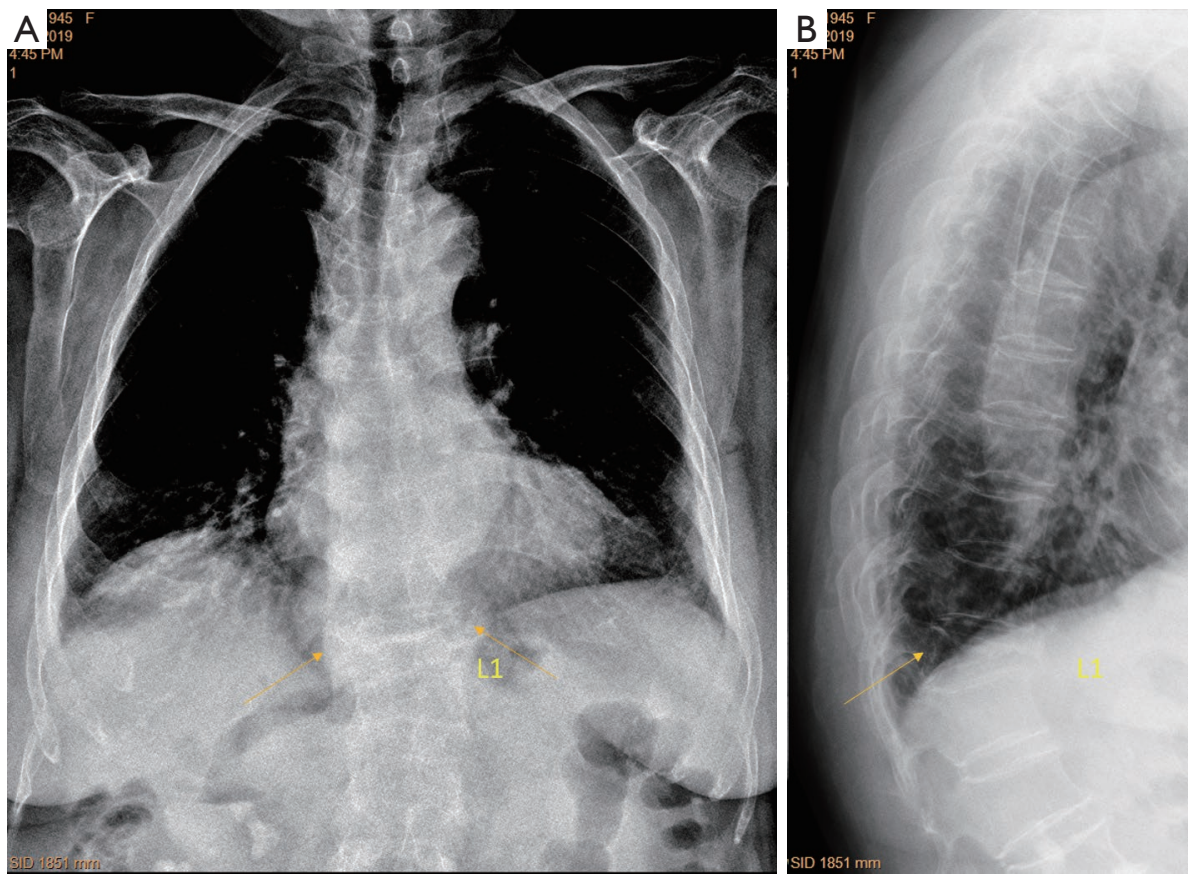

Figure 12 Chest radiographs of a female aged 75 years (A: FR, B: LR). FR shows L1 collapse (arrow) which is also shown on LR. FR, frontal radiograph; LR, lateral radiograph. 

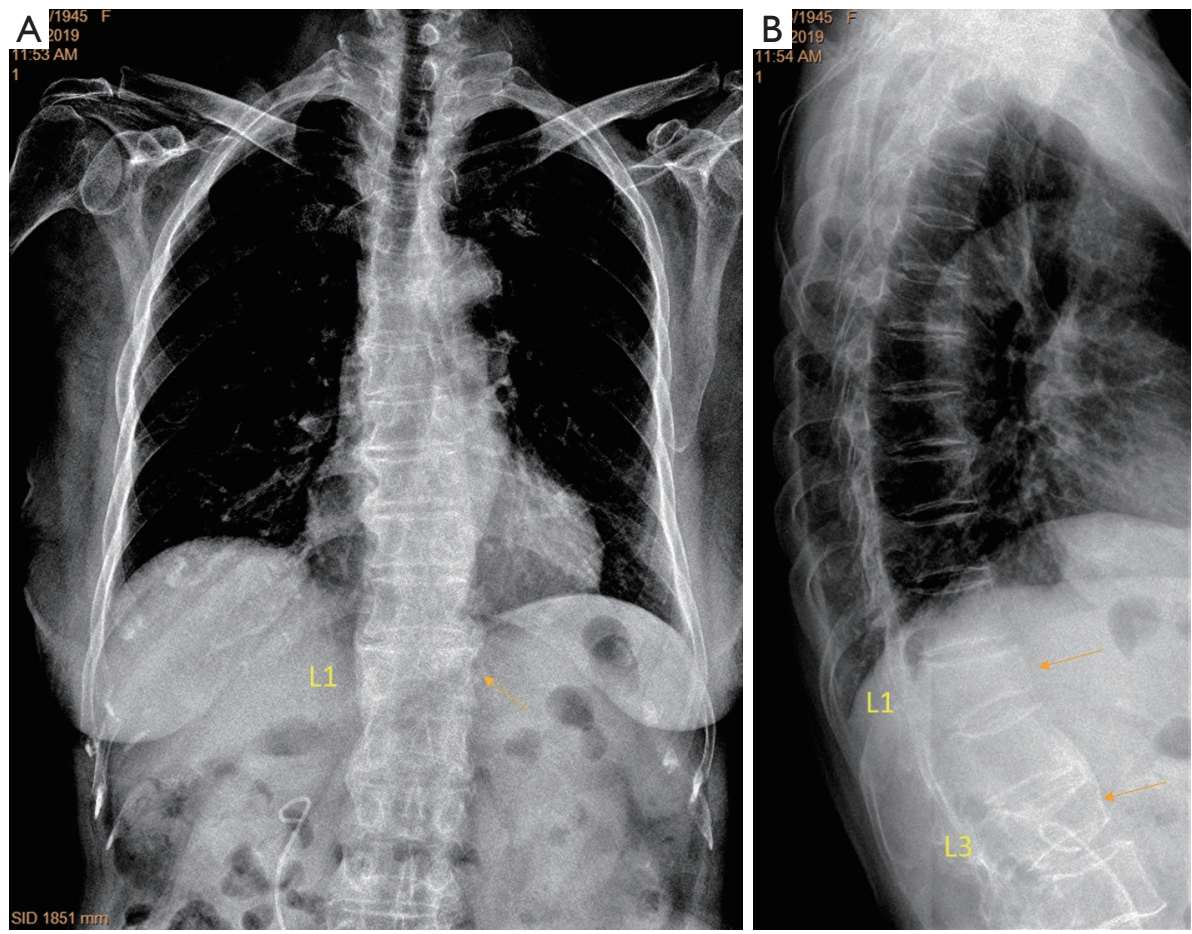

Figure 13 Chest radiographs of a female aged 75 years (A: FR, B: LR). FR shows suggested L1 VD (arrow) which is confirmed on LR (mod/ m deformity). LR shows L3 eSQ mod/s VD (arrow) which cannot be assessed on FR. FR, frontal radiograph; LR, lateral radiograph; VD, vertebral deformity.
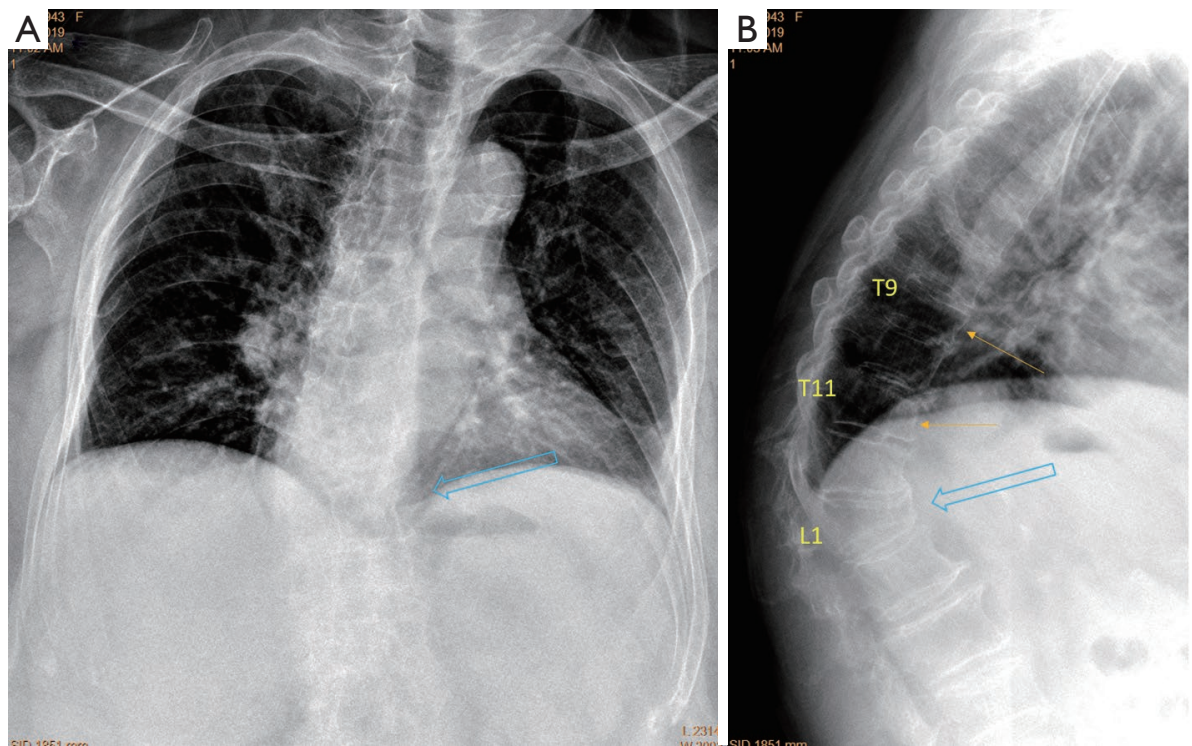

Figure 14 Chest radiographs of a female aged 77 years (A: FR, B: LR). Individual vertebrae are not well shown FR. However, a scoliosis with an angle formation (blue arrow) strongly suggest severe VD. LR shows L1 severe deformity, T9 (orange arrow), T11 (orange arrow) eSQ $\mathrm{mod} / \mathrm{s}$ and $\mathrm{mod} / \mathrm{m}$ deformity. FR, frontal radiograph; LR, lateral radiograph; VD, vertebral deformity. 

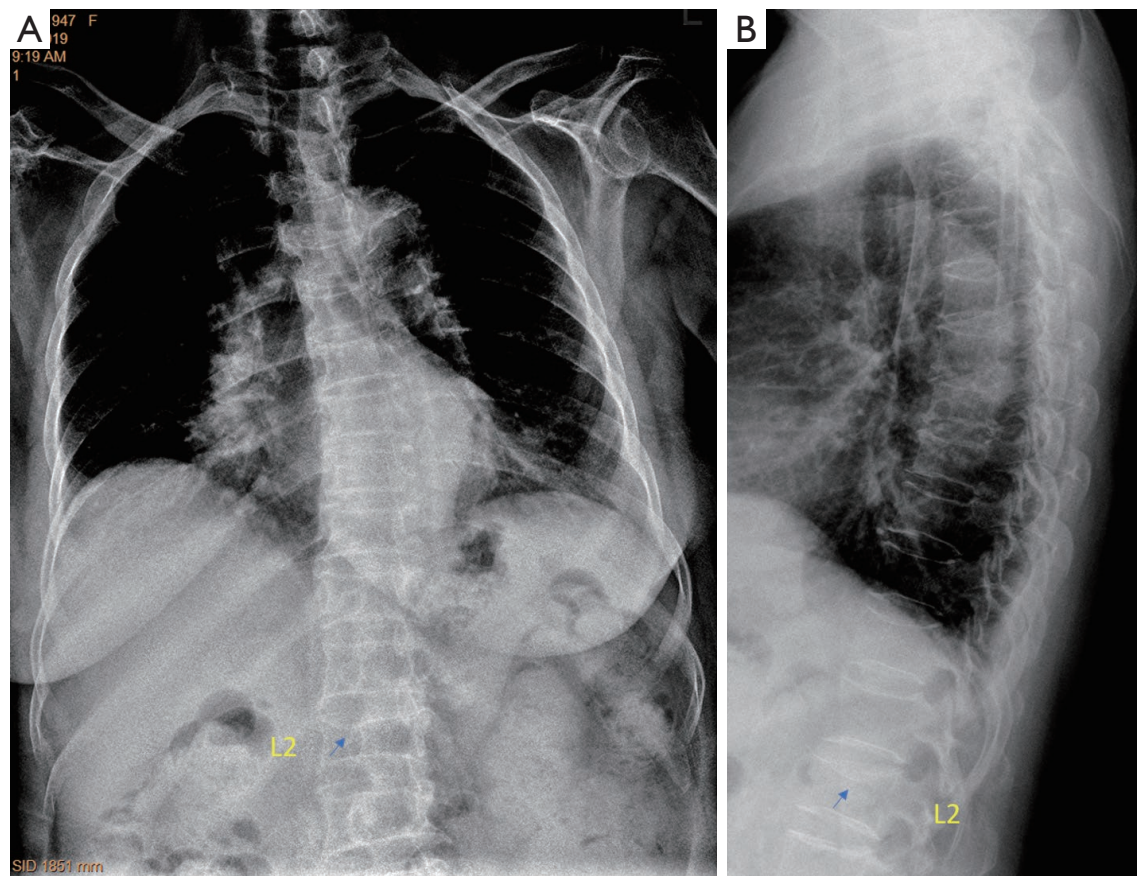

Figure 15 Chest radiographs of a female aged 73 years (A: FR, B: LR). L2 VD (arrow) is noted on FR. LR shows L2 eSQ mod/m VD with upper endplate fracture. FR, frontal radiograph; LR, lateral radiograph; VD, vertebral deformity.
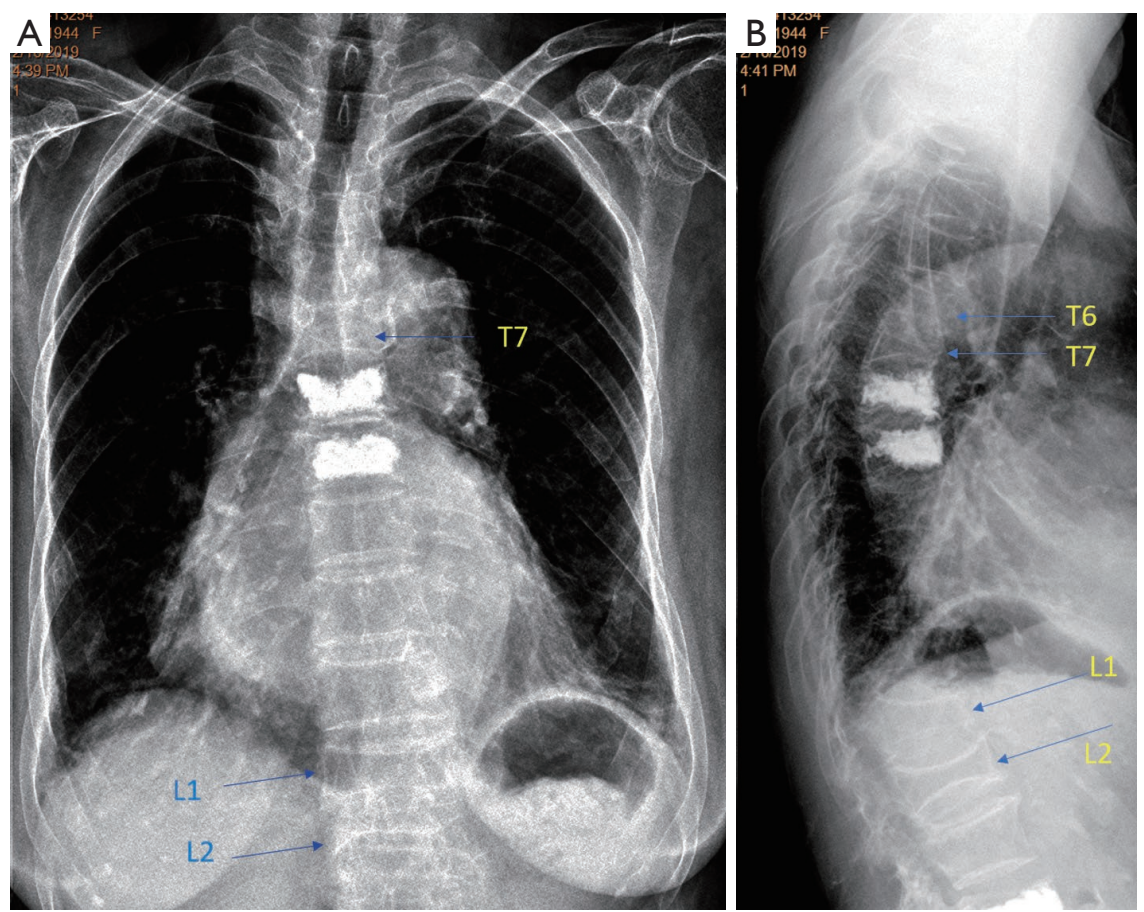

Figure 16 Chest radiographs of a female aged 76 years (A: FR, B: LR). VD of T7 (arrow), L1 (arrow) and L2 (arrow) are noted on FR, with LR confirmed eSQ T7 severe VD (arrow), L1 mod/s VD (arrow), and L2 severe VD (arrow). Injected cement (after vertebroplasty or kyphoplasty) is shown inside T8, T9 and L4 vertebral bodies. T6 VD, which is shown as eSQ mod/m grade VD on LR (arrow), cannot be evaluated on FR. FR, frontal radiograph; LR, lateral radiograph; VD, vertebral deformity. 

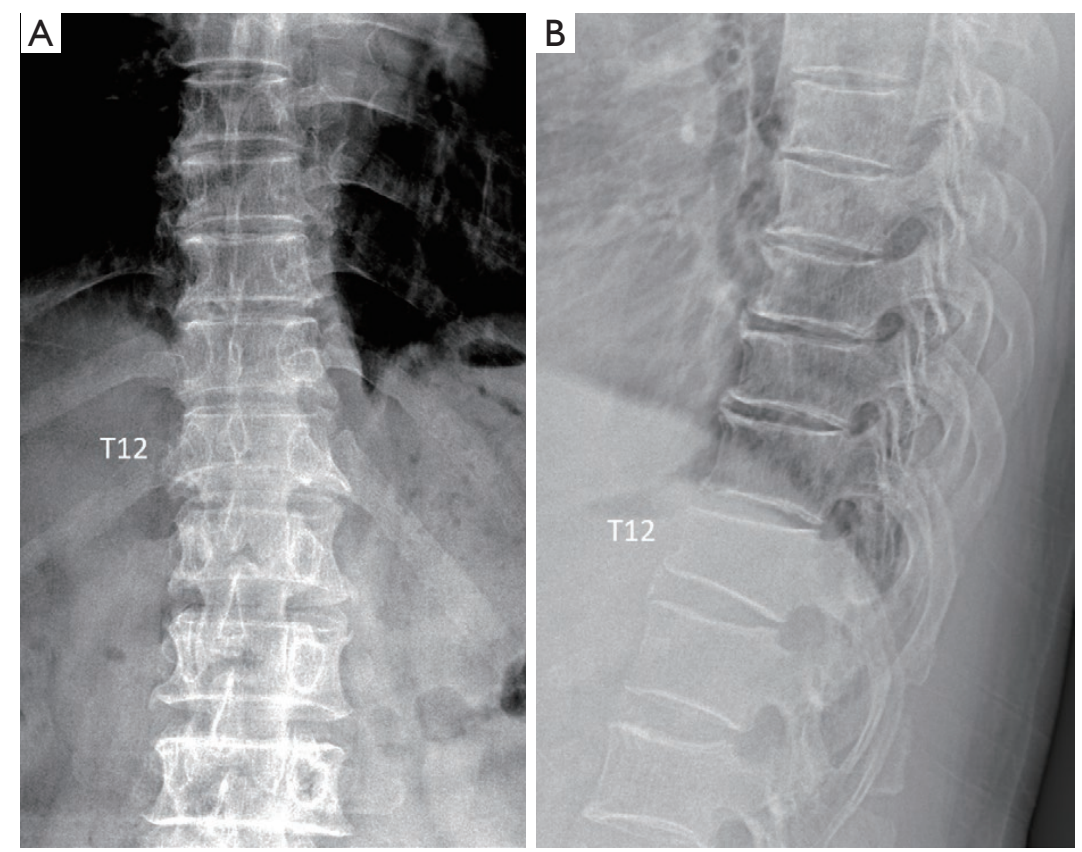

Figure 17 Spine radiograph (A: FR, B: LR). LR shows T12 eSQ mild VD. T12 VD is barely recognisable on FR by comparing it with the normal appearance of T11 and L1. It is expected that this mild VD could not be reliably evaluated on chest FR indicated for lungs. FR, frontal radiograph; LR, lateral radiograph; VD, vertebral deformity.
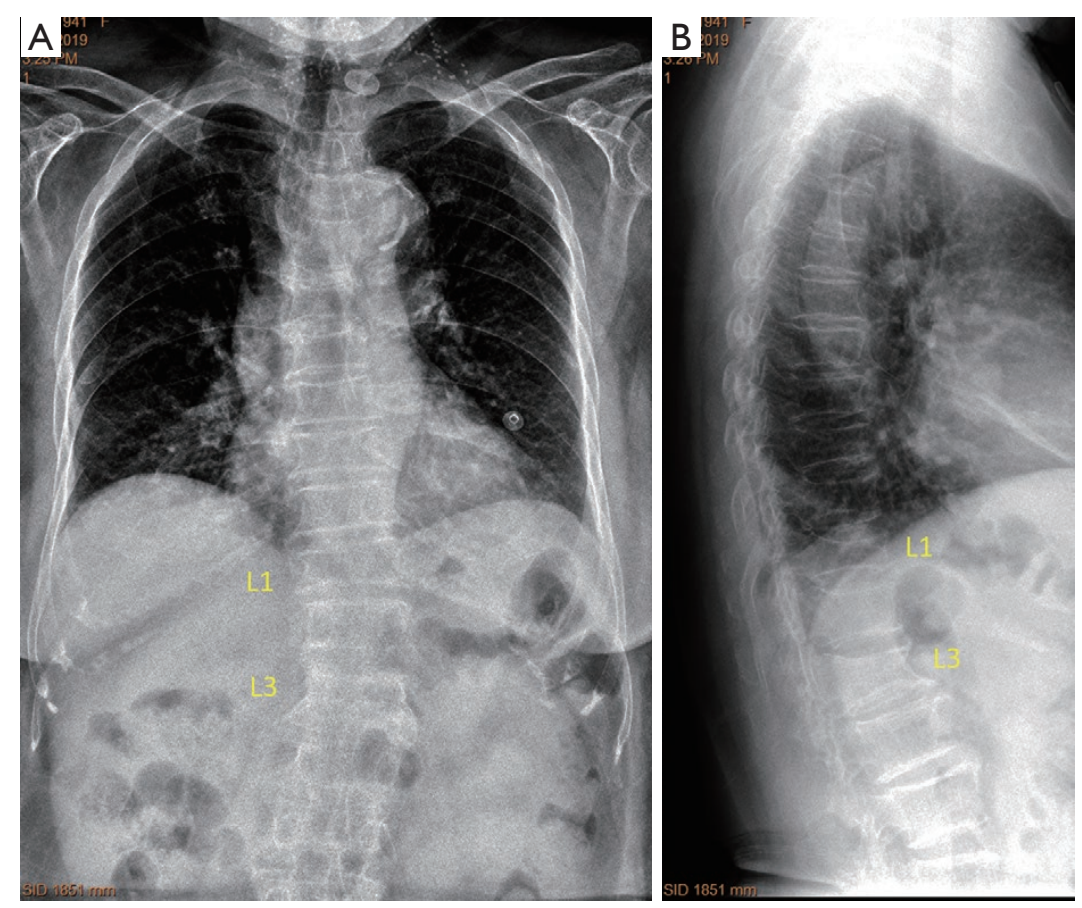

Figure 18 Chest radiographs of a female aged 79 years (A: FR, B: LR). VD of L3 can be highly suspected on FR with possible deformed shaped and higher density (suggesting collapsed bone). VD of L1 can be highly suspected on FR by comparing its shape with those of T12 and L2. This case illustrates the importance of comparing the shape and density of a suspected VD with those of its adjacent vertebrae. FR, frontal radiograph; LR, lateral radiograph; VD, vertebral deformity. 

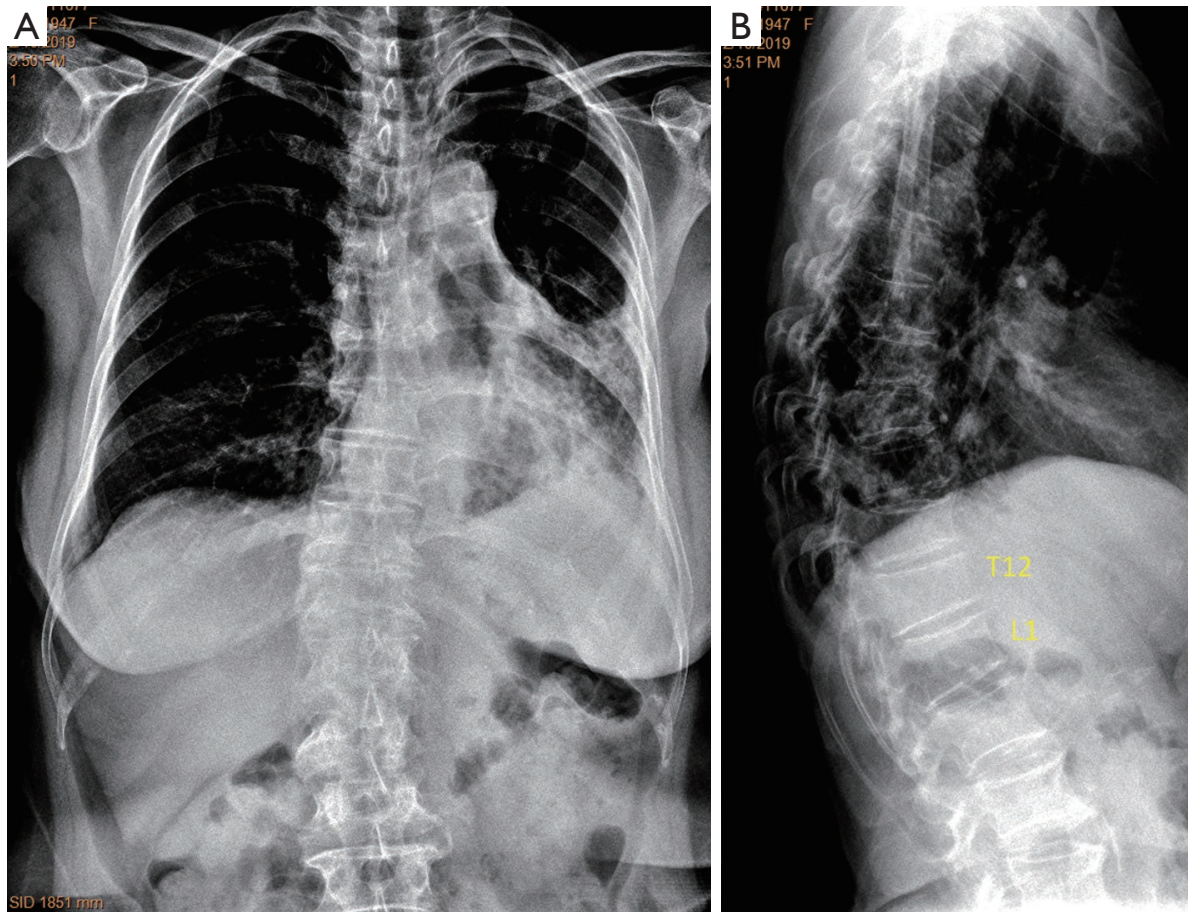

Figure 19 Chest radiographs of a female aged 73 years (A: FR, B: LR). LR shows T12 and L1 minimal grade VD, which cannot be evaluated on FR. In the meantime, L2 and L3 are poorly displayed on FR, misinterpretation of them as VD should be avoided. FR, frontal radiograph; LR, lateral radiograph; VD, vertebral deformity.
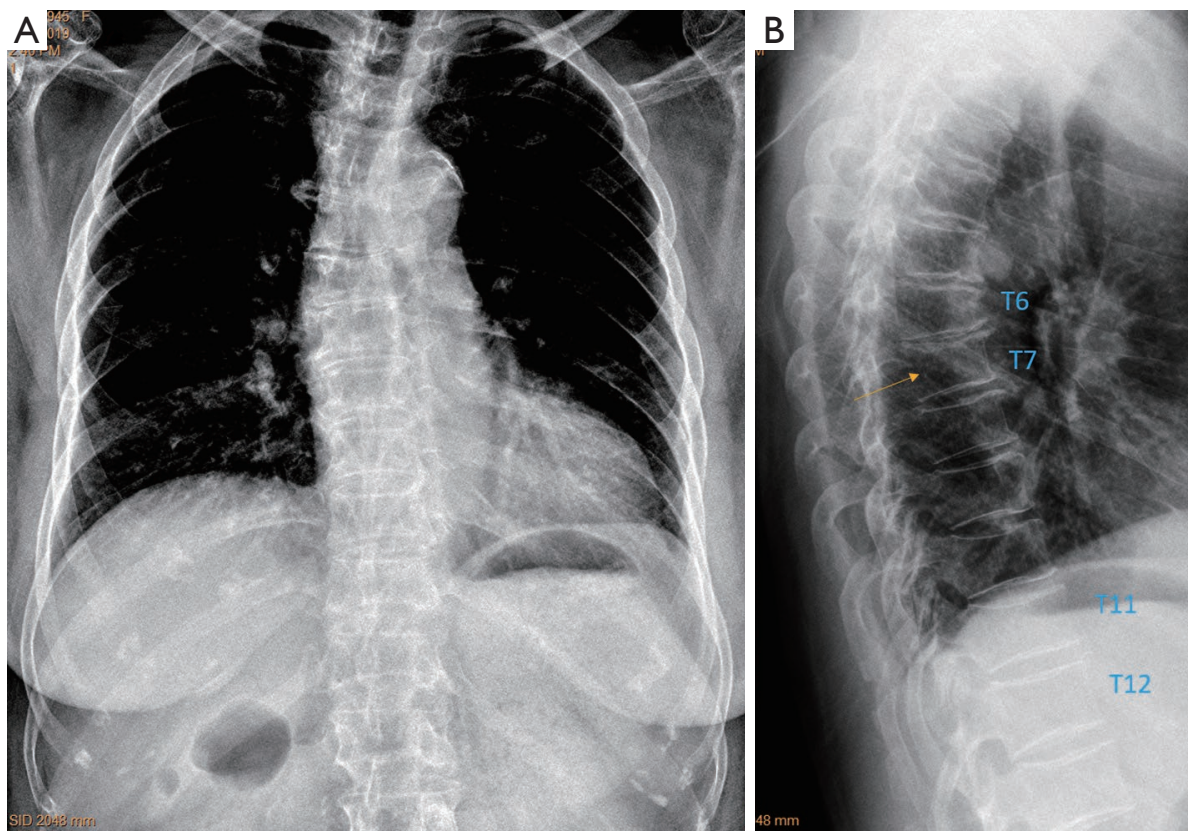

Figure 20 Chest radiographs of a female aged 75 years (A: FR, B: LR). FR shows there is eSQ minimal grade VD for T6, T7 (arrow), T11, T12. These VDs cannot be properly evaluated on FR. FR, frontal radiograph; LR, lateral radiograph; VD, vertebral deformity. 

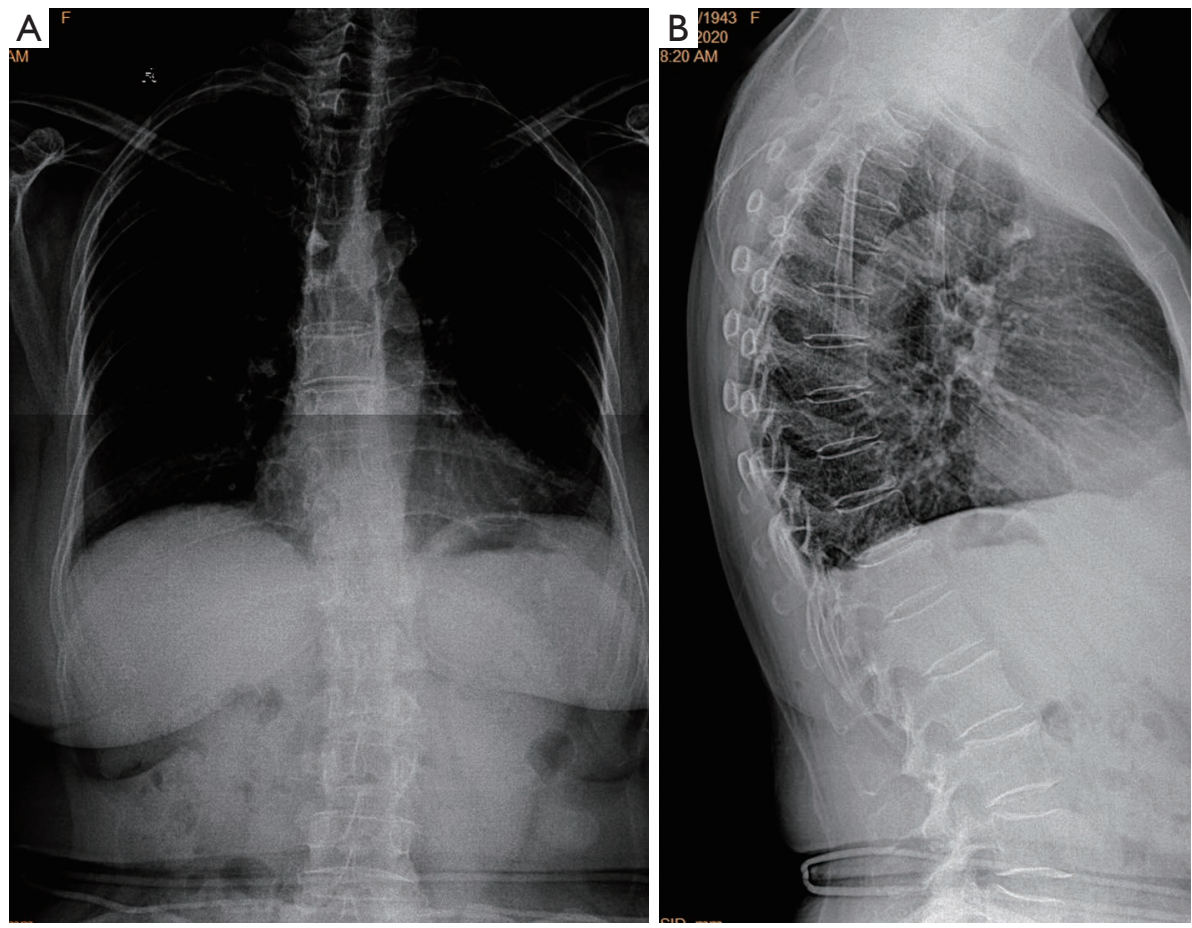

Figure 21 Chest radiographs of a female aged 77 years (A: FR, B: LR). LR shows there is no there is no VD observed. While mid-thoracic vertebral bodies show normal shape on FR, the thoracolumbar region's vertebrae are very blurred due to X-ray projection. Over-call of VD at thoracolumbar region should be avoided for such a case. FR, frontal radiograph; LR, lateral radiograph; VD, vertebral deformity.
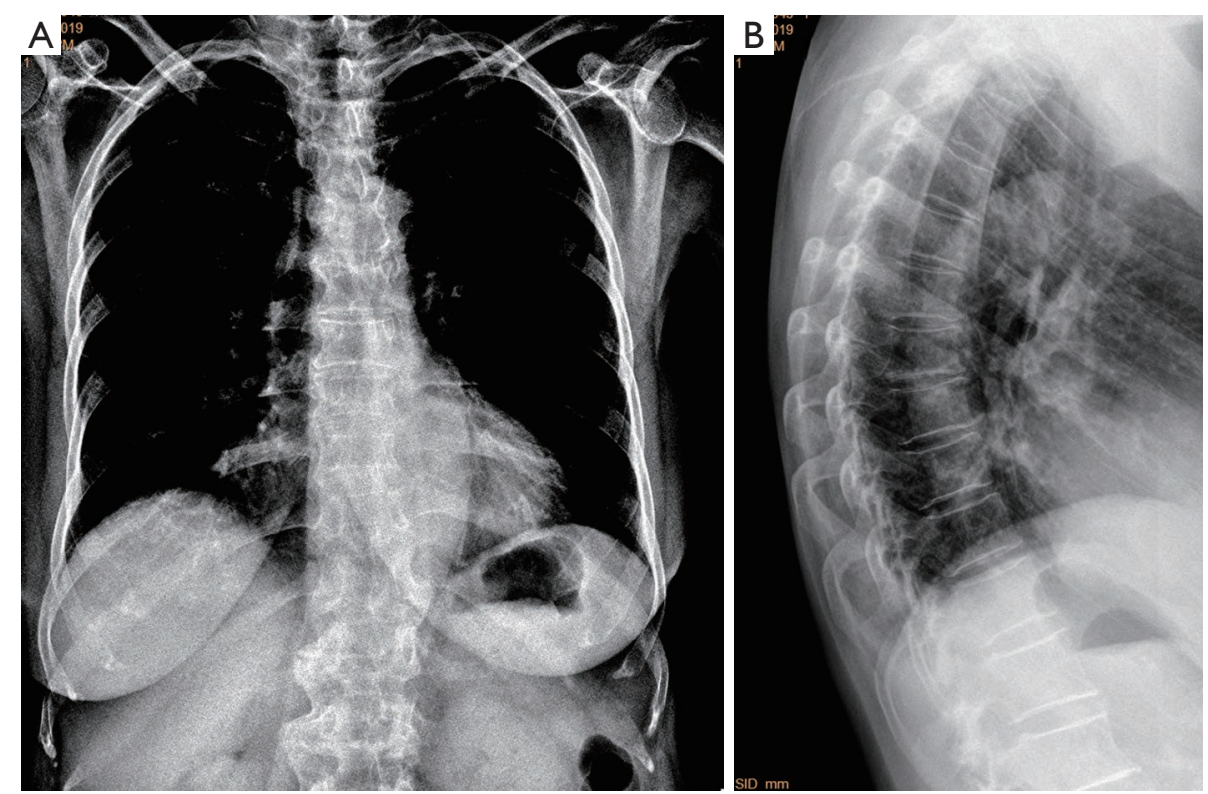

Figure 22 Chest radiographs of a female aged 75 years (A: FR, B: LR). LR shows there is no VD observed. Mid-thoracic vertebral bodies show normal shape on FR. Due to X-ray projection, the thoracolumbar region's vertebrae cannot be evaluated individually on FR. Over-call of VD at thoracolumbar region should be avoided for such a case. FR, frontal radiograph; LR, lateral radiograph; VD, vertebral deformity. 

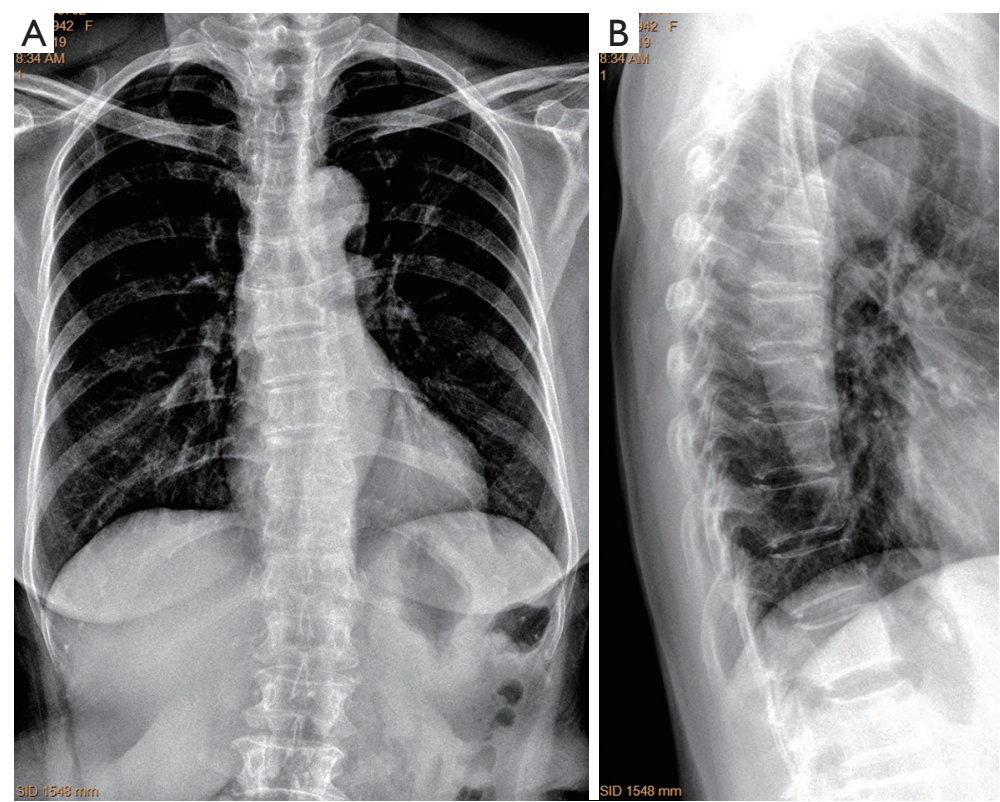

Figure 23 Chest radiographs of a female aged 78 years (A: FR, B: LR). Due to X-ray projection, there is a risk that T12 may be mislabelled as VD. Note T11 and T12 vertebral bodies have similar shape. Over-call of VD at thoracolumbar region should be avoided for such a case. FR, frontal radiograph; LR, lateral radiograph; VD, vertebral deformity.

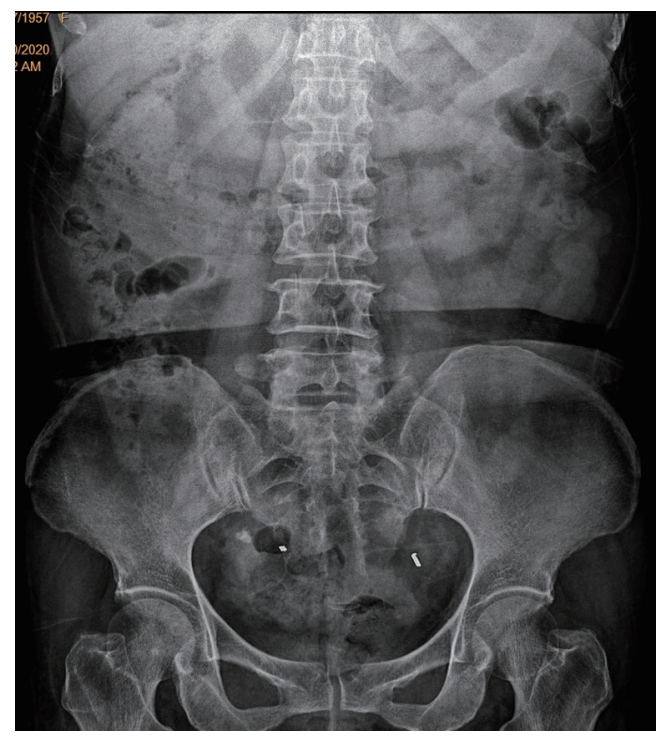

Figure 24 Abdominal FR of a female aged 63 years. L1-L5 vertebrae are well displayed with no deformity noted. LR confirmation was not obtained for this patient. FR, frontal radiograph; LR, lateral radiograph. 


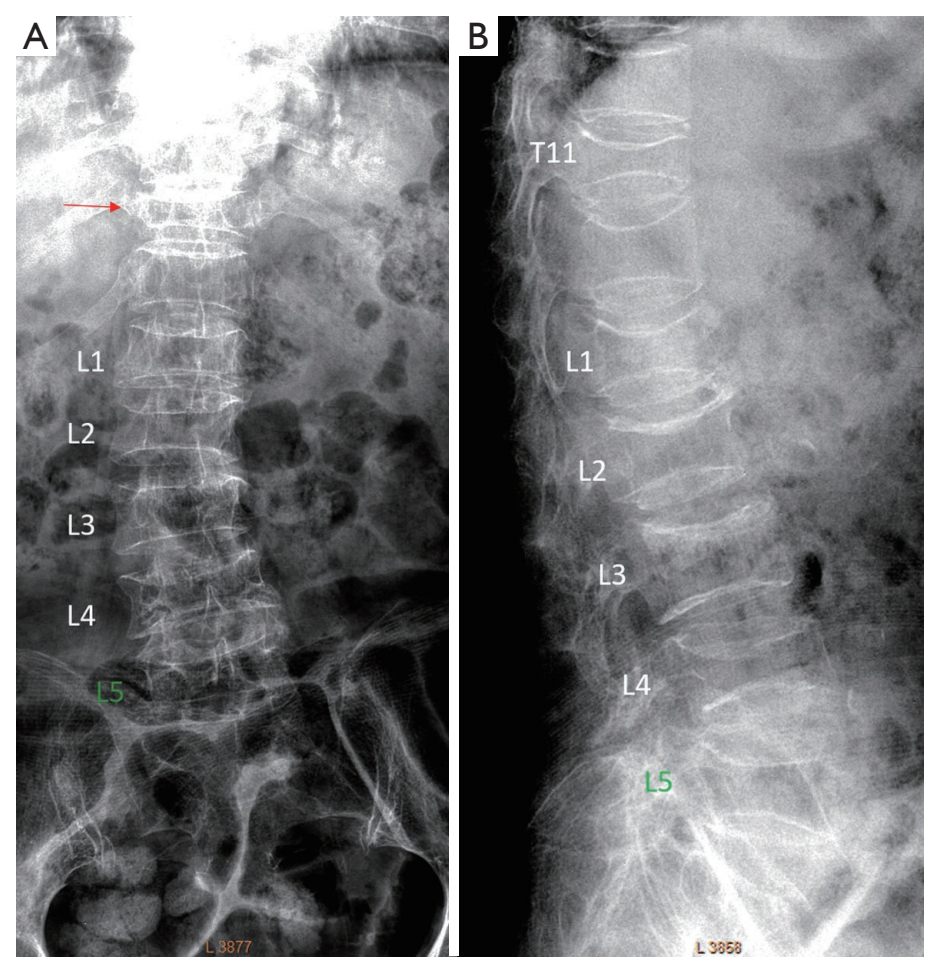

Figure 25 Spine radiograph (A: FR, B: LR). In addition to T11 eSQ severe VD (arrow), L1-L5 shows multiple deformities with endplate depression. FR, frontal radiograph; LR, lateral radiograph; VD, vertebral deformity.
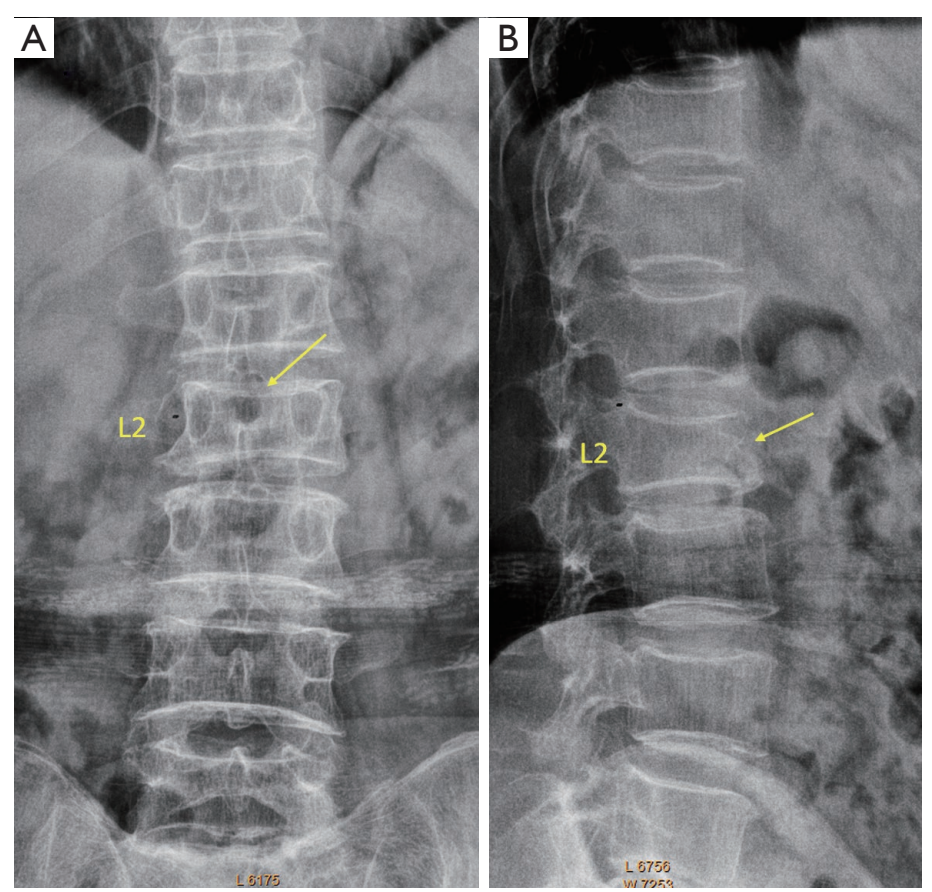

Figure 26 Spine radiographs show L2 VD. FR (A) show L2 height loss and as well as endplate depression (arrow), which is also well shown on LR (B). (B) also shows additional anterior cortex fracture (arrow). Reproduce with permission from reference (25) supplementary materials. FR, frontal radiograph; LR, lateral radiograph; VD, vertebral deformity. 

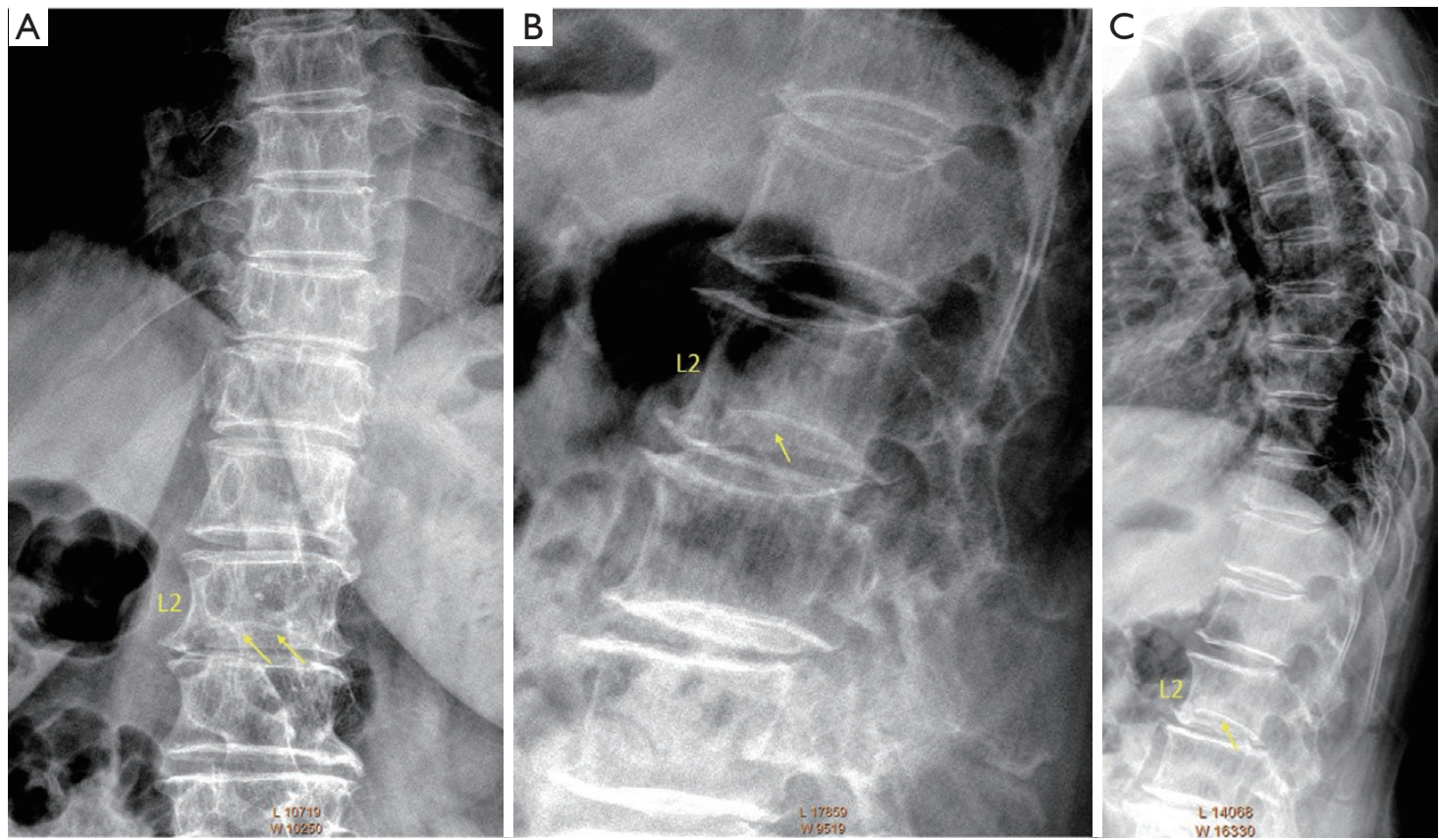

Figure 27 Spine radiographs show L2 lower endplate fracture with minimal vertebral height loss. FR (A) show L2 lower endplate fracture (arrows). This can be appreciated by comparing the normal-appearing lower endplates of L1 and L3. LR (B,C) shows apparent endplate fracture (arrow). (B) shows a zoomed-in image of L2. Reproduce with permission from reference (25) supplementary materials. FR, frontal radiograph; LR, lateral radiograph.

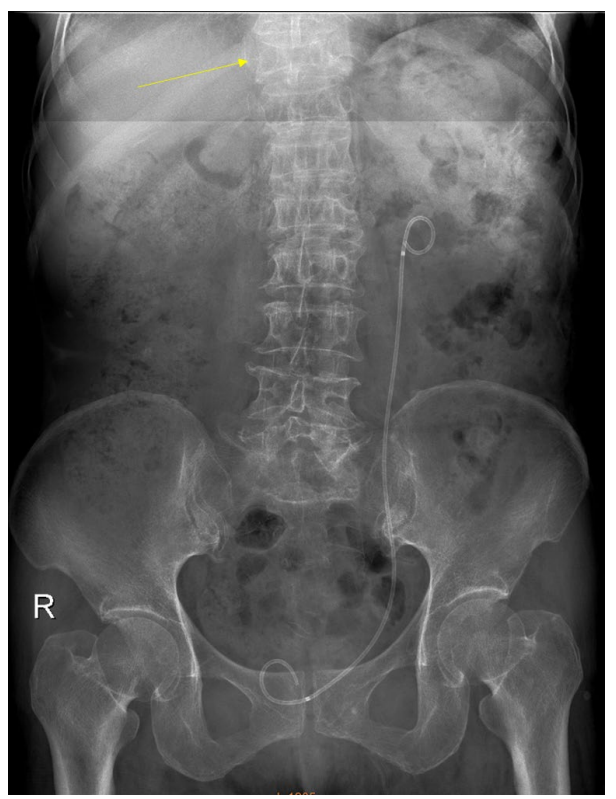

Figure 28 Abdominal FR of a 71 years old female, compressive VD of T10 is noted (arrow). A left urinary tract drainage catheter can be seen. LR confirmation was not obtained for this patient. Reproduced with permission from reference (34). FR, frontal radiograph; LR, lateral radiograph; VD, vertebral deformity.

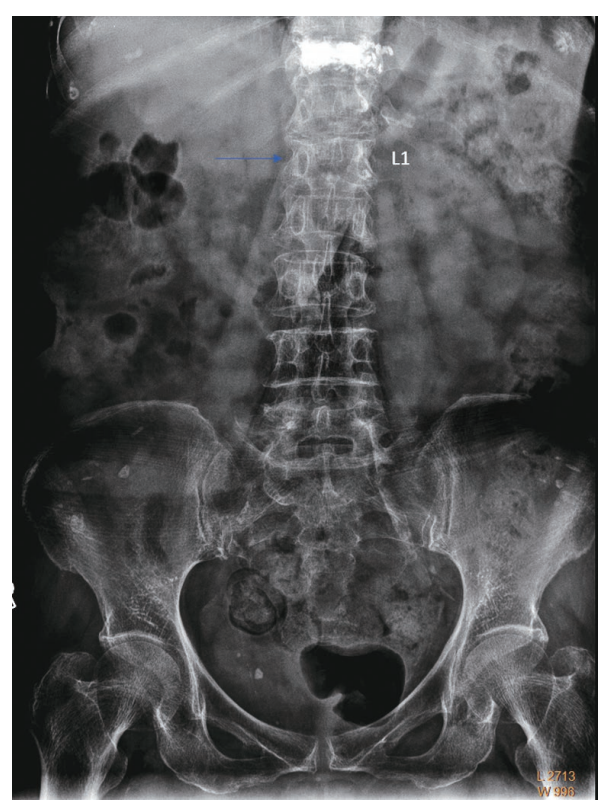

Figure 29 Abdominal FR of a female aged 78 years. T11 shows injected cement after vertebroplasty or kyphoplasty. Arrow shows VD of L1. LR confirmation was not obtained for this patient. FR, frontal radiograph; LR, lateral radiograph; VD, vertebral deformity. 


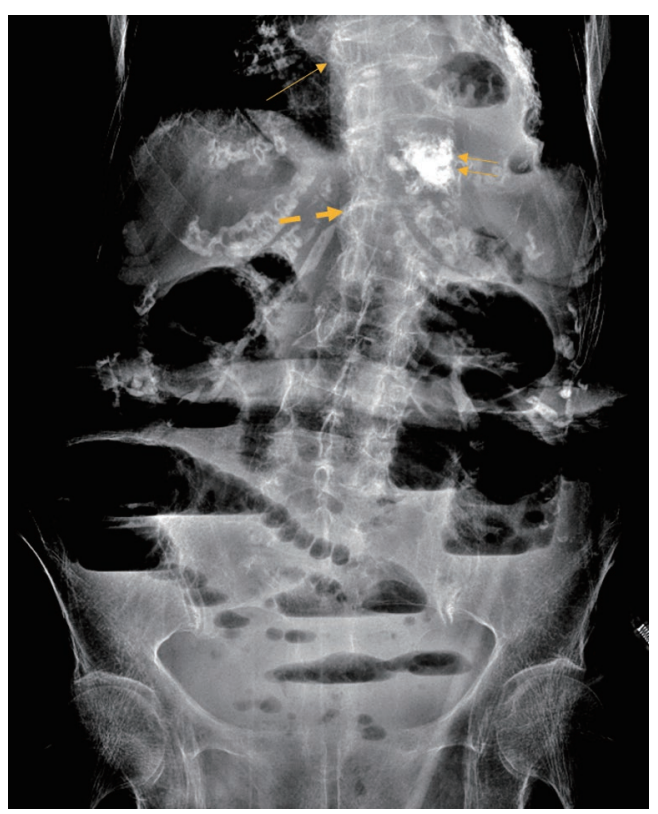

Figure 30 Standing abdominal FR of a female aged 90 years with bowel obstruction. Thoracolumbar junction has kyphosis and scoliosis. Double arrows indicate injected cement after vertebroplasty or kyphoplasty. Thin arrow indicates a definite VD. Thick dotted arrow suggests a vertebra with severe or collapsed deformity. LR confirmation was not obtained for this patient. FR, frontal radiograph; LR, lateral radiograph; VD, vertebral deformity.

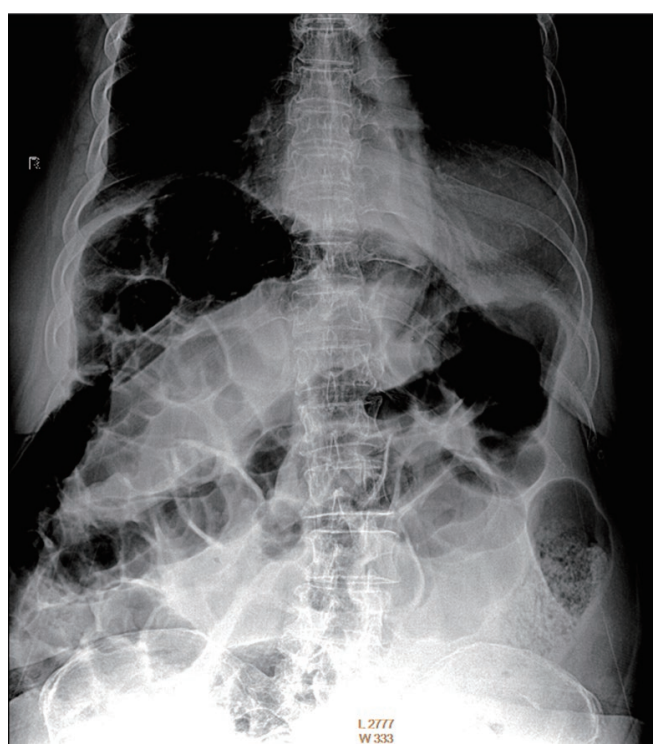

Figure 31 Abdominal FR of a female aged 70 years. T5-L4 vertebrae are displayed with no deformity observed. Bowel distention and extensive gas collection are noted. LR confirmation was not obtained for this patient. FR, frontal radiograph; LR, lateral radiograph.

\section{Acknowledgments}

Funding: This study is partially supported by ITF project of Hong Kong SAR (code: ITS/334/18).

\section{Footnote}

Conflicts of Interest: All authors have completed the ICMJE uniform disclosure form (available at http://dx.doi. org/10.21037/qims-2020-28). YXJW serves as unpaid Editor-In-Chief of Quantitative Imaging in Medicine and Surgery. JG serves as an unpaid editorial board member of Quantitative Imaging in Medicine and Surgery. The other authors have no conflicts of interest to declare.

Open Access Statement: This is an Open Access article distributed in accordance with the Creative Commons Attribution-NonCommercial-NoDerivs 4.0 International License (CC BY-NC-ND 4.0), which permits the noncommercial replication and distribution of the article with the strict proviso that no changes or edits are made and the original work is properly cited (including links to both the formal publication through the relevant DOI and the license). See: https://creativecommons.org/licenses/by-nc-nd/4.0/.

\section{References}

1. Weaver J, Sajjan S, Lewiecki EM, Harris ST, Marvos P. Prevalence and Cost of Subsequent Fractures Among U.S. Patients with an Incident Fracture. J Manag Care Spec Pharm 2017;23:461-71.

2. Delmas PD, Genant HK, Crans GG, Stock JL, Wong M, Siris E, Adachi JD. Severity of prevalent vertebral fractures and the risk of subsequent vertebral and nonvertebral fractures: results from the MORE trial. Bone 2003;33:522-32.

3. Sanchez-Rodriguez D, Bergmann P, Body JJ, Cavalier E, Gielen E, Goemaere S, Lapauw B, Laurent MR, Rozenberg S, Honvo G, Beaudart C, Bruyère O. The Belgian Bone Club 2020 guidelines for the management of osteoporosis in postmenopausal women. Maturitas 2020;139:69-89.

4. Danila MI, Saag KG. Imminent Fracture Risk: A Call to Action for Rheumatologists. Arthritis Care Res (Hoboken) 2020;72:741-3.

5. Nuti R, Brandi ML, Checchia G, Di Munno O, Dominguez L, Falaschi P, Fiore CE, Iolascon G, Maggi S, Michieli R, Migliaccio S, Minisola S, Rossini M, Sessa 
G, Tarantino U, Toselli A, Isaia GC. Guidelines for the management of osteoporosis and fragility fractures. Intern Emerg Med 2019;14:85-102.

6. Singer A, Exuzides A, Spangler L, O'Malley C, Colby C, Johnston K, Agodoa I, Baker J, Kagan R. Burden of illness for osteoporotic fractures compared with other serious diseases among postmenopausal women in the United States. Mayo Clin Proc 2015;90:53-62.

7. Kim DH, Vaccaro AR. Osteoporotic compression fractures of the spine; current options and considerations for treatment. Spine J 2006;6:479-87.

8. Wáng YXJ, Che-Nordin N, Deng M, Leung JCS, Kwok AWL, He LC, Griffith JF, Kwok TCY, Leung PC. Osteoporotic vertebral deformity with endplate/cortex fracture is associated with higher further vertebral fracture risk: the Ms. OS (Hong Kong) study results. Osteoporos Int 2019;30:897-905.

9. Crandall CJ, Newberry SJ, Diamant A, Lim YW, Gellad WF, Booth MJ, Motala A, Shekelle PG. Comparative effectiveness of pharmacologic treatments to prevent fractures: an updated systematic review. Ann Intern Med 2014;161:711-23.

10. Viswanathan M, Reddy S, Berkman N, Cullen K, Middleton JC, Nicholson WK, Kahwati LC. Screening to Prevent Osteoporotic Fractures: Updated Evidence Report and Systematic Review for the US Preventive Services Task Force. JAMA 2018;319:2532-51.

11. Agency for Healthcare Research and Quality. Pathways to Prevention (P2P). Workshop draft systematic evidence review: long-term drug therapy and drug holidays for osteoporosis fracture prevention. Available online: https:// effectivehealthcare.ahrq.gov/products/osteoporosisfracture-prevention Accessed on 25 Aug 2020.

12. Committee on Practice Bulletins-Gynecology, The American College of Obstetricians and Gynecologists. ACOG Practice Bulletin N 129. Osteoporosis. Obstetrics and Gynecology 2012;120:718-34.

13. Fink HA, MacDonald R, Forte ML, Rosebush CE, Ensrud KE, Schousboe JT, Nelson VA, Ullman K, Butler M, Olson CM, Taylor BC, Brasure M, Wilt TJ. Long-Term Drug Therapy and Drug Discontinuations and Holidays for Osteoporosis Fracture Prevention: A Systematic Review. Ann Intern Med 2019;171:37-50.

14. Howe TE, Shea B, Dawson LJ, Downie F, Murray A, Ross C, Harbour RT, Caldwell LM, Creed G. Exercise for preventing and treating osteoporosis in postmenopausal women. Cochrane Database Syst Rev 2011;(7):CD000333. 15. Levis S, Theodore G. Summary of AHRQ's comparative effectiveness review of treatment to prevent fractures in men and women with low bone density or osteoporosis: update of the 2007 report. J Manag Care Pharm 2012;18:S1-15.

16. Conley RB, Adib G, Adler RA, Åkesson KE, Alexander IM, Amenta KC, Blank RD, Brox WT, Carmody EE, Chapman-Novakofski K, Clarke BL, Cody KM, Cooper C, Crandall CJ, Dirschl DR, Eagen TJ, Elderkin AL, Fujita M, Greenspan SL, Halbout P, Hochberg MC, Javaid M, Jeray KJ, Kearns AE, King T, Koinis TF, Koontz JS, Kužma M, Lindsey C, Lorentzon M, Lyritis GP, Michaud LB, Miciano A, Morin SN, Mujahid N, Napoli N, Olenginski TP, Puzas JE, Rizou S, Rosen CJ, Saag K, Thompson E, Tosi LL, Tracer H, Khosla S, Kiel DP. Secondary Fracture Prevention: Consensus Clinical Recommendations from a Multistakeholder Coalition. J Bone Miner Res 2020;35:36-52.

17. Ensrud KE, Blackwell TL, Fink HA, Zhang J, Cauley JA, Cawthon PM, Black DM, Bauer DC, Curtis JR, Orwoll ES, Barrett-Connor E, Kado DM, Marshall LM, Shikany JM, Schousboe JT; Osteoporotic Fractures in Men (MrOS) Research Group. What Proportion of Incident Radiographic Vertebral Fractures in Older Men Is Clinically Diagnosed and Vice Versa: A Prospective Study. J Bone Miner Res 2016;31:1500-3.

18. Fink HA, Milavetz DL, Palermo L, Nevitt MC, Cauley JA, Genant HK, Black DM, Ensrud KE; Fracture Intervention Trial Research Group. What proportion of incident radiographic vertebral deformities is clinically diagnosed and vice versa? J Bone Miner Res 2005;20:1216-22.

19. Guggina P, Flahive J, Hooven FH, Watts NB, Siris ES, Silverman S, Roux C, Pfeilschifter J, Greenspan SL, Díez-Pérez A, Cooper C, Compston JE, Chapurlat R, Boonen S, Adachi JD, Anderson FA Jr, Gehlbach S; GLOW Investigators. Characteristics associated with anti-osteoporosis medication use: data from the Global Longitudinal Study of Osteoporosis in Women (GLOW) USA cohort. Bone 2012;51:975-80.

20. Kwok TCY, Law SW, Leung EMF, Choy DTK, Lam PMS, Leung JCS, Wong SH, Ip TP, Cheung CL. Hip fractures are preventable: a proposal for osteoporosis screening and fall prevention in older people. Hong Kong Med J 2020;26:227-35.

21. US Preventive Services Task Force, Curry SJ, Krist AH, Owens DK, Barry MJ, Caughey AB, Davidson KW, Doubeni CA, Epling JW Jr, Kemper AR, Kubik M, Landefeld CS, Mangione CM, Phipps MG, Pignone M, Silverstein M, Simon MA, Tseng CW, Wong JB. Screening 
for Osteoporosis to Prevent Fractures: US Preventive Services Task Force Recommendation Statement. JAMA 2018;319:2521-31.

22. Brincat M, Calleja-Agius J, Erel CT, Gambacciani M, Lambrinoudaki I, Moen MH, Schenck-Gustafsson K, Tremollieres F, Vujovic S, Rees M, Rozenberg S; EMAS. EMAS position statement: Bone densitometry screening for osteoporosis. Maturitas 2011;68:98-101.

23. Cheng X, Yuan H, Cheng J, Weng X, Xu H, Gao J, Huang M, Wáng YXJ, Wu Y, Xu W, Liu L, Liu H, Huang C, Jin Z, Tian W; on behalf of Bone and Joint Group of Chinese Society of Radiology, Chinese Medical Association (CMA), Musculoskeletal Radiology Society of Chinese Medical Doctors Association, Osteoporosis Group of Chinese Orthopedic Association, Bone Density Group of Chinese Society of Imaging Technology, CMA. Chinese expert consensus on the diagnosis of osteoporosis by imaging and bone mineral density. Quant Imaging Med Surg 2020;10:2066-77.

24. International Society for Clinical Densitometry 2019 ISCD Official Positions-Adult. International Society for Clinical Densitometry (ISCD). Available online: https://www.iscd.org/official-positions/2019-iscd-officialpositions-adult/ Accessed on 25 Aug 2020.

25. Wáng YXJ, Du MM, Che-Nordin N, Ye PP, Qiu SW, Griffith JF, Yan ZH. Recognizing osteoporotic vertebral deformity on frontal view radiograph: a cohort analysis and a pictorial review. Arch Osteoporos 2020;15:41.

26. Wu CH, Tu ST, Chang YF, Chan DC, Chien JT, Lin CH, Singh S, Dasari M, Chen JF, Tsai KS. Fracture liaison services improve outcomes of patients with osteoporosisrelated fractures: A systematic literature review and metaanalysis. Bone 2018;111:92-100.

27. Jensen AL, Lomborg K, Wind G, Langdahl BL. Effectiveness and characteristics of multifaceted osteoporosis group education--a systematic review. Osteoporos Int 2014;25:1209-24.

28. Morfeld JC, Vennedey V, Müller D, Pieper D, Stock S. Patient education in osteoporosis prevention: a systematic review focusing on methodological quality of randomised controlled trials. Osteoporos Int 2017;28:1779-803.

29. Wáng YXJ, Wang XR, Che-Nordin N, Xu FR, Huang

Cite this article as: Wáng YXJ, Du EZ, Gong J, Cheng X. Interpretation of osteoporotic vertebral deformity on frontal view radiographs of the chest and abdomen: a pictorial review. Quant Imaging Med Surg 2021;11(1):423-442. doi: 10.21037/qims2020-28
QL. On the possibility of over-diagnosis of osteoporotic vertebral fracture at mid-thoracic level. J Thorac Dis 2019;11:5708-11.

30. Freitas SS, Barrett-Connor E, Ensrud KE, Fink HA, Bauer DC, Cawthon PM, Lambert LC, Orwoll ES; Osteoporotic Fractures in Men (MrOS) Research Group. Rate and circumstances of clinical vertebral fractures in older men. Osteoporos Int 2008;19:615-23.

31. Lentle B, Trollip J, Lian K. The Radiology of Osteoporotic Vertebral Fractures Redux. J Clin Densitom 2016;19:40-7.

32. Wáng YXJ. A modified semi-quantitative (mSQ) grading scheme for osteoporotic vertebral fracture in elderly women. Quant Imaging Med Surg 2019;9:146-50.

33. Wáng YXJ, Santiago FR, Deng M, Nogueira-Barbosa MH. Identifying osteoporotic vertebral endplate and cortex fractures. Quant Imaging Med Surg 2017;7:555-91.

34. Ruiz Santiago F, Láinez Ramos-Bossini AJ, Wáng YXJ, López Zúñiga D. The role of radiography in the study of spinal disorders. Quant Imaging Med Surg 2020. doi: 10.21037/qims-20-1014

35. Wáng YXJ, Diacinti D, Yu W, Cheng XG, NogueiraBarbosa MH, Che-Nordin N, Guglielmi G, Ruiz Santiago F. Semi-quantitative grading and extended semiquantitative grading for osteoporotic vertebral deformity: a radiographic image database for education and calibration. Ann Transl Med 2020;8:398.

36. Wáng YXJ, Lentle BC. Radiographic osteoporotic vertebral fractures in elderly men: a brief review focusing on differences between the sexes. Quant Imaging Med Surg 2020;10:1863-76.

37. Wáng YXJ, Che-Nordin N, Leung JCS, Kwok TCY. Existing severe osteoporotic vertebral fractures in elderly Chinese males were only weakly associated with higher further vertebral fracture risk at year-4 follow-up. Osteoporos Int 2020;31:1593-4.

38. Deng M, Zeng XJ, He LC, Leung JCS, Kwok AWL, Griffith JF, Kwok T, Leung PC, Wáng YX. Osteoporotic vertebral fracture prevalence in elderly Chinese men and women: a comparison of endplate/cortex fracture-based and morphometrical deformity-based methods. J Clin Densitom 2019;22:409-19. 